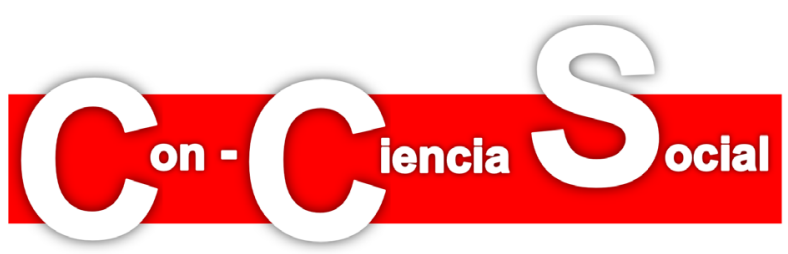

\title{
Consideraciones críticas sobre la mundialización de los sistemas educativos: Jesús Romero, Inés Dussel y Thomas S. Popkewitz
}

\author{
Critical considerations about the globalization of education \\ systems: Jesús Romero, Inés Dussel y Thomas S. Popkewitz
}

\author{
Raimundo Cuesta \\ Fedicaria-Salamanca \\ raicuesta2@gmail.com
}

Marta Estellés

Fedicaria-Cantabria

marta.estelles@gmail.com

Recibido en octubre de 2019

Aceptado en noviembre de 2019

DOI:10.7203/con-cienciasocial.3.16791

\section{RESUMEN}

Esta sección trata de complementar el título del presente número de nuestra revista (Conocimiento, poder y mundialización), trasladando la problemática genérica sugerida en el mismo a un tema cada vez más sobresaliente en la era de la globalización y del totalcapitalismo, a saber, la progresiva mundialización de la omnipresente razón escolarizadora nacida en los albores de la modernidad occidental. Ciertamente, la aproximación crítica a esta cuestión se puede realizar desde distintas ópticas y especialidades académicas. Por nuestra parte, hemos optado en esta ocasión por la colaboración, a través de una suerte de mesacoloquio, de tres personas muy descollantes en el campo de lo que podríamos llamar historia del curriculum. Se trata, por orden de aparición en este número, de Jesús Romero (España), Inés Dussel (México) y Thomas S. Popkewitz (Estados Unidos).

Palabras clave:
$\begin{aligned} & \text { escolarización, } \\ & \text { totalcapitalismo. }\end{aligned}$

\begin{abstract}
This section complements the generic title of this issue of our journal (Knowledge, power and globalization), moving the generic issue to an increasingly prominent topic in the era of globalization and total capitalism, namely the progressive globalization of the ubiquitous school reason born at the dawn of Western modernity. Certainly, the critical approach to this issue can be made from different perspectives and academic specialties. We have opted on this occasion for the collaboration, through a colloquium, of three outstanding scholars in the field of curriculum history. They are Jesús Romero (Spain), Inés Dussel (Mexico) and Thomas S. Popkewitz (United States)
\end{abstract}

Keywords: globalization, schooling, curriculum history, total capitalism.

\section{Referencia}

Cuesta, R. y Estellés, M. (coords.) (2020). Consideraciones críticas sobre la mundialización de los sistemas educativos: Jesús Romero, Inés Dussel y Thomas S. Popkewitz. Con-Ciencia Social (segunda época), 3, 77-126. DOI:10.7203/con-cienciasocial.3.16791 


\section{Presentación}

Esta sección trata de complementar el título del presente número de nuestra revista (Conocimiento, poder y mundialización), trasladando la problemática genérica sugerida en el mismo a un tema cada vez más sobresaliente en la era de la globalización y del totalcapitalismo, a saber, la progresiva mundialización de la omnipresente razón escolarizadora nacida en los albores de la modernidad occidental. La lógica de la escolarización a menudo se presenta como una verdad dada, natural e incontrovertible, omitiendo que posee una historia y un desarrollo complejos. Más allá de las apariencias, el isomorfismo de los sistemas nacionales de educación de nuestro tiempo se debe a la influencia de una poderosa tecnoburocracia alojada en instituciones internacionales dedicadas al diseño, asesoramiento y evaluación de las políticas educativas. Empero subsisten, a pesar de todo, variantes y resistencias locales irreductibles.

La pesquisa histórica y comparada de los sistemas educativos ha favorecido la aparición de una mirada sinóptica e interactiva entre la escala global y la local. En el mundo de la historiografía más general, la llamada Global History ha sido una respuesta tentativa y llena de paradojas a la necesidad de comprender el mundo como un todo integrado. Desde luego, en el ámbito de la escuela y del curriculum el estudio de los sistemas nacionales de educación insertos en un entramado de relaciones internacionales aparece como un objeto de estudio cultivado cada vez con mayor intensidad como consecuencia de unas políticas educativas progresivamente más pergeñadas y gobernadas desde organismos transnacionales.

No obstante, creemos que el discurso imperante acerca de una historia universal como proceso unitario progresivo y como despliegue de Occidente es incompatible con el pensamiento crítico. En realidad, constituye poco más que una excrecencia de un desacreditado paradigma difusionista, que, a pesar de todo, es doctrina hegemónica entre las administraciones educativas de hoy, que persisten en una óptica euroamericana de la historia universal. Ciertamente, la fuerte expansión de las instituciones educativas integradas y gestionadas directa o indirectamente por el Estado favorece una organización y funcionamiento del campo de la educación como sistemas nacionales, a imagen y semejanza de los que empezaron a erigirse primero en Europa y luego en América durante el siglo XIX. Su éxito mundial ha llevado a un consenso transcultural e implícito sobre la escolarización de masas, un dogma simplificador acerca de la escuela como institución benefactora universal y fomentadora del desarrollo económico y social. 
Raimundo Cuesta y Marta Estellés, Consideraciones críticas sobre la mundialización...

Frente a todo ello, el análisis histórico de la escolarización de masas y las modalidades de arquitectura institucional y de conocimiento que la apuntalan permite comprobar, comparar y definir modelos nacionales que, a su vez, nos autorizan a afinar o simplemente deshacer la predominante imagen mecanicista, todavía subyacente. $\mathrm{Y}$ así, más que un mecanismo autopropulsado de racionalidad teleológica, los llamados sistemas educativos nacionales y el formato curricular de los mismos significan totalidades históricas, dinámicas, contradictorias y contingentes, que se materializan y expresan en estados-nación pero que nunca se explican al margen de procesos de estandarización curricular y de evaluación de los resultados escolares a escala mundial. Toda aproximación a este fenómeno no puede dejar de ser relacional e histórica.

Ciertamente, la aproximación crítica a estos problemas se puede realizar desde distintas ópticas y especialidades académicas. Por nuestra parte, hemos optado en esta ocasión por la colaboración, a través de una suerte de mesa-coloquio, de tres personas muy descollantes en el campo de lo que podríamos llamar historia del curriculum. Tal adscripción se sitúa más allá de las disputas terminológicas habidas entre los que prefieren hablar de "historia de la educación", sintagma de uso más común en España, o de los que se inclinan por "historia del curriculum, rubro más empleado en la tradición anglosajona (véase Cuesta, 2020). Se trata, por orden de aparición en este número, de Jesús Romero (Universidad de Cantabria, España), Inés Dussel (DIE-CINVESTAV, México) y Thomas S. Popkewitz (Universidad de Wisconsin-Madison, Estados Unidos).

Romero y Dussel, pertenecientes a la misma generación, respondieron brillantemente y con precisión al cuestionario que les hicimos llegar y cuyas respuestas insertamos literalmente en esta parte de la revista. En cambio, Thomas Popkewitz, nacido en 1940, pertenece a otra cohorte generacional muy distinta, uno de los más prominentes padres fundadores del campo de la historia del curriculum desde esa atalaya mundial que es la Universidad de Wisconsin-Madison, eligió otra manera de participar en el coloquio. Él optó por tomar el cuestionario como incentivo para construir su propio discurso sobre el tema abordado, de modo que su contribución formalmente se parece más a un artículo que a una entrevista. No obstante, respetamos escrupulosamente su voluntad porque su colaboración enriquece notablemente el conjunto de la revista aportando un texto original (que se facilita también en inglés mediante un enlace). A los tres debemos manifestar nuestro mucho agradecimiento por su desinteresada colaboración con Con-Ciencia Social. 
También en este capítulo debe quedar subrayada nuestra deuda con Miguel Ángel Pereyra, máximo representante hispano e introductor en España de la historia del curriculum (véase Luis y Romero, 2006). Gracias a su ayuda se favorecieron los contactos oportunos y además tuvo la gentileza de revisar la traducción al español del texto de su amigo y maestro Thomas S. Popkewitz.

La primera entrevista corresponde a Jesús Romero, nacido en 1968 y que actualmente desempeña su trabajo como profesor titular de Didáctica de las Ciencias Sociales en el Departamento de Educación de la Universidad de Cantabria, institución en la que se formó y desde la que pronto, en compañía de Alberto Luis Gómez y dentro del grupo Asklepios, integrado en Fedicaria, realizó una brillante carrera profesional. Ese espléndido itinerario se integra durante los años noventa en el activo foco de investigadores cántabros coordinados por Alberto Luis Gómez, que encadenaron un abanico de investigaciones de doctorado gracias a las cuales se amplió la mirada y el contenido de la didáctica de las ciencias sociales en España, dando al mismo tiempo un impulso muy notable a la historia del curriculum. Interesado inicialmente por el alcance de las nuevas tecnologías en la enseñanza (Romero, 2001), su contribución ha sido muy importante con miras a la excogitación de las leyes que rigen la producción histórica del conocimiento escolar. Cabe destacar, entre sus abundantes obras, el libro Escuela para todos. Conocimiento académico y geografía escolar en España (Luis y Romero, 2007). Se diría que el núcleo "cántabro" de Fedicaria se inclinó tempranamente por la vía de escudriñar las materias de enseñanza dentro del paradigma de la historia del curriculum, adscribiéndose preferentemente a coordenadas anglosajonas (Luis y Romero, 2007). Por lo demás, siguiendo esa línea, el profesor Romero recientemente participó en la elaboración de un estado de la cuestión internacional sobre el tema (Romero y Estellés, 2020).

La segunda entrevista tiene a Inés Dussel como protagonista. Esta historiadora, muy conocida internacionalmente, nació en 1966 en Estados Unidos, pero muy pronto fue a residir a Argentina, país en donde se formó y transcurrió parte muy importante de su carrera docente e investigadora. Lo que no fue óbice para que su formación también tuviera lugar en la Universidad de Wisconsin-Madison bajo la tutela precisamente de Thomas S. Popkewitz. En cierto modo, como su maestro, ella es un tipo de intelectual de la era de la globalización, cuyas actividades investigadoras y docentes se reparten por varias universidades del mundo, quizás con especial relevancia en la Facultad Latinoamericana de Ciencias Sociales (FLACSO) en su sede de Buenos Aires. Tampoco es fácil delimitar su especificidad investigadora porque 
Raimundo Cuesta y Marta Estellés, Consideraciones críticas sobre la mundialización...

esta profesora ha dedicado su vida a temas muy diversos, todos ellos quizá englobables dentro de una "historia cultural" (véase Popkewitz y otros, 2003), que entiende el curriculum como un artefacto cultural (material y simbólico). Desde una primera línea que entiende la escuela como máquina de producción de conciencias y de prácticas pedagógicas en el aula (Dussel y Caruso, 2000) se va pasando a otra concepción cada vez más sutil que explora las formas materiales y mentales de la cultura escolar (Dussel, 2003). Recientemente ha volcado su interés hacia los medios y las formas de educación a través de la imagen.

Finalmente, Thomas S. Popkewitz, nacido en 1940, participa en el coloquio con una aportación muy personal que condensa una buena parte de su copioso aparato conceptual (systems of reason, el curriculum como alquimia, cosmopolitismo, epistemología social, gubernamentalidad, política de la representación, ciencia crítica de la educación, historia del presente, etc.) de inequívocas resonancias foucaultianas, que a lo largo del tiempo ha ido jalonando su fructífera vida profesional. Hablar de este autor es hablar de la Universidad de Wisconsin, como principal núcleo motor del giro acontecido desde los años sesenta del siglo pasado en la historia del curriculum a escala mundial. Thomas S. Popkewitz, profesor en la Universidad de WisconsinMadison (allí donde se cruzan una parte de los caminos más influyentes de la encrucijada de la historia del curriculum) convivió en esa universidad con personas de la talla intelectual de Herbert Kliebard (gran precursor de la historia del curriculum) y con Barry M. Franklin. En los años ochenta estos tres pioneros publican obras de obligada referencia que marcan un antes y un después en el estudio del curriculum y las disciplinas escolares. En la misma institución trabajaba, en una línea neomarxista, Michael Apple. El punto de vista metodológico de Popkewitz recoge, en cambio, la tradición de la historia social pero reconvirtiéndola en "historia cultural" mediante la incrustación de acusadas vetas posmodernas y foucaultianas (véase Popkewitz y otros, 2003). Según su punto de vista, el curriculum ha de ser considerado como epistemología social (Popkewitz, 2003b, p. 117).

En su condición de "intelectual global", ha trillado un campo muy extenso y sin fronteras prefijadas de los curriculum studies y de la historia de la escolarización, llevando su voz a países de muy distinta índole cultural merced al tejido de una tupida red de influencias e interacciones dentro de la que, a modo de ejemplo, se han creado algunos polos muy prominentes como los que representan Inés Dussel en México o Miguel A. Pereyra en España (Luzón y Torres, 2012). El propio Popkewitz (2017), cuyas trayectoria y obras han sido abundantemente traducidas y conocidas en 
Raimundo Cuesta y Marta Estellés, Consideraciones críticas sobre la mundialización...

España, se reconoce como un defensor de una historia comparada y una perspectiva transnacional en el campo de los estudios curriculares.

\section{CONTRIBUCIÓN AL DEBATE SOBRE LA MUNDIALIZACIÓN DE LOS SISTEMAS EDUCATIVOS DE... JESÚS ROMERO}

Pregunta: Después de cuatro décadas de enfoques historiográficos inclinados hacia lo microhistórico y lo cultural, en la actualidad se aprecia una resurrección de las perspectivas, como la Global History, que reclaman una visión sinóptica y una temporalidad de larga duración. ¿Hasta qué punto en la historia del curriculum se está produciendo un giro "global" de las investigaciones?

Respuesta: Existen suficientes indicios para sostener que, aunque con mucho retraso (más adelante aclararé esta valoración), ese "giro" se ha iniciado ya. Pero hasta donde alcanza mi pobre conocimiento- diría que aún está en ciernes, a la vista de su lentitud y de su alcance limitado, cuando no controvertible.

En el campo de los estudios del currículum, el ejemplo más notorio (y pionero) ha sido el proyecto internacional de investigación comparada, fundamentado en la sociología histórica neoinstitucionalista y liderado desde la Universidad de Stanford por John W. Meyer y Francisco O. Ramírez, que se puso en marcha durante la década de 1980 con un amplio apoyo financiero, proporcionado principalmente por la National Science Foundation de EE.UU., pero también por la Hoover Institution y el Center for Research in International Studies de Stanford, la Spencer Foundation, el Banco Mundial o la Sociedad Japonesa para la promoción de la Ciencia. Esta aproximación desde la teoría neoinstitucionalista cuestionó las interpretaciones del currículum de los sistemas educativos contemporáneos inspiradas en el funcionalismo -bajo cuya lente se ha visto como un mecanismo de integración social y de solidaridad nacional en poblaciones crecientemente diferenciadas- o en las teorías de la reproducción que lo han analizado como un vehículo de los valores dominantes al servicio del mantenimiento de las estructuras y hegemonías sociales-, por su excesiva simplificación y por la insuficiente atención prestada al contenido y al formato de su base cultural. Saludó a la, por entonces, flamante historia social del currículum por su visión más compleja de la formación y dinámica interna de este dispositivo, pero objetó su confinamiento a la escala estatal o local. Frente a tales miradas, y tomando como punto de partida el constatable despliegue a escala planetaria de la escolarización de masas, presentaron la evolución de los patrones curriculares como un proceso de 
Raimundo Cuesta y Marta Estellés, Consideraciones críticas sobre la mundialización...

creciente isomorfismo transnacional, como un movimiento mundial en el cual se ha asociado el conocimiento para las masas con modelos o esquemas estandarizados de progreso educativo y social.

A los neoinstitucionalistas les debemos aportaciones ciertamente interesantes. Pero su enfoque está lastrado por algunos sesgos muy discutibles que han sido objeto de críticas, a mi juicio merecidas. En primer lugar, el sesgo teleológico implícito en su narrativa sobre el desarrollo de la "sociedad mundial" y de la educación institucionalizada en su seno. Sin ir más lejos, su dibujo de los procesos de cambio curricular no consigue librarse de la mistificación del destino manifiesto, toda vez que da pábulo a la impresión ficticia de un camino lineal y siempre en ascenso hacia cotas de perfección creciente. No es de extrañar que Carney, Rappleye y Silova (2013) hayan acusado a estos estudios de ver "el mundo social a través del reconfortante marco del "capitalismo liberal". En segundo lugar, y de manera relacionada, la sinécdoque en la que incurren. Sus análisis sobre el isomorfismo curricular se basan en el examen de la retórica y formalidad expresa de los planes de estudio oficiales aprobados en los distintos países del orbe. El problema es que la confluencia en los significantes (una afirmación empírica que se han esforzado en verificar) no conlleva necesariamente una correspondencia en los significados (una hipótesis sin contrastar). No debería soslayarse que el sentido de las palabras no es independiente de las prácticas sociales de significación, y éstas están siempre situadas en contextos histórico-sociales concretos. Esto es, son tributarias de unas dinámicas heredadas, de unas circunstancias materiales determinadas, de unos u otros equilibrios de poder, de unos $\mathrm{u}$ otros ordenamientos institucionales, de unas estructuras culturales y mentales con rasgos específicos... que interaccionan con -y modulan- las tendencias generales, dando lugar a distintas variantes, materializaciones, ritmos temporales... En suma, a distintas respuestas, ora adaptativas, ora proactivas, ora reactivas.

Lo cual no impide reconocer la ineludible necesidad, siquiera complementaria, de una perspectiva analítica "global" para comprender los derroteros de los sistemas escolares estatales modernos. No ya sólo en esta "era de la globalización", en los siglos $\mathrm{XX}$ y $\mathrm{XXI}$, sino también en el siglo $\mathrm{XIX}$. Y esto, me parece, es algo que las historias de la educación "nacionales" han tardado demasiado en calibrar convenientemente. En la introducción de su interesante obra La transformación del mundo. Una historia global del siglo XIX, traducida al castellano en 2015, el historiador alemán Jürgen Osterhammel sostenía del siguiente modo la imposibilidad de escribir una historia del siglo XIX que no sea universal: 
Raimundo Cuesta y Marta Estellés, Consideraciones críticas sobre la mundialización...

"... al buscar las huellas tempranas de la "globalización», los historiadores actuales no son los primeros en descubrir en el siglo XIX — que a menudo, y con razón, ha sido definido como el "siglo del nacionalismo y los estados nacionales»relaciones transfronterizas: transnacionales, transcontinentales, transculturales. En efecto, muchos contemporáneos ya entendieron que el siglo se caracterizaba en especial por la ampliación de los horizontes de pensamiento y actuación. Entre las capas medias y bajas de Europa y Asia, muchas personas dirigieron la mirada y la esperanza hacia países remotos de los que se hablaba bien; muchos millones se atrevieron a emprender viajes a lo desconocido. Estadistas y militares aprendieron a pensar en categorías de «política mundial». En ese siglo surgió el British Empire, el primer imperio verdaderamente mundial de la historia, que ahora incluía también Australia y Nueva Zelanda. Otros imperios tuvieron la ambición de medirse con el modelo británico. El comercio y las finanzas se concentraron más que los de la Edad Moderna hasta formar un sistema-mundo integrado. Para 1910, los cambios económicos que se producían en Johannesburgo, Buenos Aires o Tokio se registraban en el acto en Hamburgo, Londres o Nueva York. Los científicos reunían datos y objetos en todo el mundo y estudiaban las lenguas, costumbres y religiones de los pueblos más distantes. Los críticos del orden mundial imperante empezaron a organizarse también en el plano internacional -a menudo, más allá de Europa-: obreros, mujeres, pacifistas, antirracistas, anticolonialistas. El siglo XIX reflejó su propia globalidad emergente."

Salvando las distancias, esto es aplicable también a la educación. Las fórmulas organizativas y curriculares se aprendieron y emularon, las aspiraciones políticas, sociales, económicas y/o culturales subyacentes a las mismas se difundieron -bien que leídas y acogidas de maneras harto dispares- de unas latitudes a otras, las ideas circularon, agentes cualificados viajaron y crearon redes... La imitación de los modelos que, por unas razones $\mathrm{u}$ otras, se convirtieron en referentes (en diferentes momentos y espacios lo han sido el alemán, norteamericano, francés, inglés, japonés...); el hecho de que, en un marco de agudizada rivalidad imperialista, las innovaciones educativas introducidas en algunas de las naciones dominantes acabasen fijando el estándar para aquellas otras deseosas de no quedar rezagadas; la dependencia de las colonias con respecto a su metrópoli; la mimetización de algunas soluciones y convenciones por parte de los países independizados en el XIX, $y$ después en el $X X$, con vistas a lograr reconocimiento interno y externo en tanto que verdaderos estados-nación, etc. son factores que actuaron -de manera variable, 
muchas veces contradictoria, conflictiva, incierta y, desde luego, sin desembocaduras pre-escritas o inevitables- en esa dirección. Una dirección que se ha acentuado, tras la Segunda Guerra Mundial, merced a la influencia ascendente que ha ido ganando la agenda educativa de las organizaciones multilaterales como la UNESCO, el Banco Mundial, la OCDE, la OEA, el BID o la Unión Europea. Ni siquiera el nativismo chovinista y xenófobo de la oleada de "nacionalpopulismos" (la expresión, atinada en mi opinión, es de Roger Eatwell y Matthew Goodwin, 2019) a la que estamos asistiendo en las últimas décadas, y que ya ha comenzado a impactar en la educación -véase, v.g., la nueva legislación educativa que entró en vigor en Polonia el curso 2017/2018, impulsada por el Gobierno del partido PiS (Ley y Justicia), y perfectamente "canónica" en su vocación contrarreformista y ultranacionalista-, puede entenderse sólo en clave interna: es un fenómeno internacional, con vínculos mutuos e incomprensible al margen de tendencias más generales.

La historia global ha sido presentada como un intento de superación tanto de las anteojeras nacionales como del etnocentrismo occidental. Dada la progresiva extensión e intensificación de las interconexiones e interdependencias, ello exige necesariamente -amén de desembarazarse de deslices teleológicos como el comentado- conjugar factores "multi-escala" en nuestras explicaciones de las realidades escolares, y de cualquier otra dimensión de la vida social. Por supuesto, los resultados de las interacciones entre las dinámicas generales y las particularidades locales son diversos, inciertos, contingentes y cambiantes, pero semejante constatación, crucial, no nos exime de dicha exigencia.

P.: Si se nos permite efectuar un ejercicio de máxima simplificación, los estudiosos del tema de la mundialización educativa podrían dividirse en dos grandes categorías enfrentadas: economicistas y culturalistas. Entre los primeros, se encuentran los teóricos del capital humano y de la educación como inversión productiva, así como las teorías marxistas que consideran la expansión mundial de las escuelas como un epifenómeno del capitalismo. Frente a ambas, algunas posiciones culturalistas neoweberianas, como las de la sociología neoinstitucionalista, consideran la educación como un ideal compartido y una forma de legitimación del poder gubernamental. ¿Qué tipo de perspectiva te parece más interesante?, ¿Es posible superar estos marcos interpretativos? 
Raimundo Cuesta y Marta Estellés, Consideraciones críticas sobre la mundialización...

$R$. .: Creo que seguir planteando un debate binario en términos de economía vs. cultura no ayuda en nada a la mejora de nuestra comprensión. La vida real no se guía por un esquema tan simple: un único factor no puede explicar su complejidad. Por añadidura, los distintos factores concurrentes (no reducibles a esos dos, por fundamentales que sean) interactúan entre sí, y no son fácilmente deslindables. Baste recordar, como chascarrillo indicativo, que en el corazón de la economía de libre mercado -supuestamente regida por una "mano invisible", por la "ley" de la oferta y la demanda- late un peregrino mito cultural, institucionalizado tras batalla política, según el cual la suma de egoísmos individuales conduce al bienestar colectivo. Incurre en una simplificación abusiva quien contempla la cultura como un mero subproducto de la "infraestructura" social, pero, a la inversa, solo desde una visión hipostasiada y autorreferencial de la misma cabría desanclarla de sus condiciones materiales de posibilidad e imaginarla autónoma, evolucionando de acuerdo con su propia lógica irreductible. La cuestión no está, por tanto, en decantarse por un factor u otro -un error grave, a mi juicio-, sino en: 1) analizar con mayor finura su naturaleza e incidencia, y 2) comprender mejor sus interacciones mutuas, considerando con Giddens que la "recursividad" (lo producido es, al mismo tiempo, productor de aquello que lo produce) parece un principio constitutivo de la realidad social. Iré por partes. Me referiré aquí a lo primero y dejaré lo segundo para la siguiente pregunta.

La importancia del factor económico se me antoja fuera de duda, pero su relación con la educación no es tan sencilla como la pintan las teorías clásicas del capital humano (y las versiones actuales centradas en la "economía del conocimiento"). A simple vista puede parecer obvio que una mano de obra bien formada aumenta la productividad nacional, y ello movería a invertir en la expansión de los sistemas educativos. Sin embargo, muchos estudios han puesto de relieve que el vínculo entre educación y crecimiento es más bien laxo e indirecto, condicionado a su vez por otros factores. Valga uno de los muchos ejemplos esgrimidos por el prestigioso economista de la Universidad de Cambridge, Ha-Joon Chang (2012): al principio de sus milagros económicos, los dragones asiáticos no tenían un nivel educativo singularmente alto. Bastante menor, en cualquier caso, que el de Filipinas o Argentina, a quienes no les ha ido nada bien. De hecho, según el citado autor, "para la prosperidad de un país no es tan determinante el nivel educativo de las personas como la capacidad del país para organizarlas en empresas de alta productividad". Que no es lo mismo. A pesar de lo cual, en estas últimas décadas se ha hecho cada vez más hincapié en el papel de la educación como instrumento de la política económica, en particular de las 
políticas de oferta alentadas por el credo neoliberal en respuesta a la globalización. Como los Estados carecen de poder individual para contrarrestar $-y$ de voluntad colectiva para regular- los flujos transnacionales, en su lugar se inclinan por propiciar la "adaptación" de sus ciudadanos a este escenario. En primer lugar, modificando y flexibilizando su formación para que puedan afrontar la incertidumbre asociada a la velocidad de los cambios, así como los desafíos de una competitividad exacerbada, de la automatización y de la mayor movilidad del capital industrial y financiero. $Y$, en segundo lugar, enviando señales a los mercados mundiales sobre el nivel de sus respectivos "recursos humanos". De ahí la creciente relevancia de las evaluaciones internacionales atentas a medir el caudal de "competencias clave" acumulado por niños y jóvenes. No obstante, semejante inclinación admite otra lectura. De entrada, la globalización neoliberal no es un fenómeno de la naturaleza, ni una mera consecuencia del progreso tecnológico. Tampoco una etapa inapelable de alguna supuesta ley histórica que regiría el inexorable avance del capitalismo. Como señala Chang, el mundo previo al estallido de la Primera Guerra Mundial estaba más globalizado que el de las décadas de 1960 y 1970, pese a que las tecnologías de la comunicación, la producción y el transporte eran menos sofisticadas. Tanto es así que muchos historiadores económicos se refieren al período 1870-1914 como el de la “primera globalización". El motivo es que, en los años 60, 70 y primeros 80 del siglo $\mathrm{XX}$, los gobiernos de los países centrales optaron por regular con firmeza la circulación internacional de capitales, mano de obra y bienes. Fueron las políticas desreguladoras, de mercantilización extensiva de actividades humanas y de apertura irrestricta de los mercados emprendidas a partir de los 80 las que condujeron a la globalización de la economía neoliberal. Es decir, el grado y tipo de globalización no lo determina la tecnología ni una inexistente ley económica natural, sino la política. Estirando un poco el argumento, podría conjeturarse que el capitalismo transnacional desregulado (y la educación en tanto se utilice a su servicio) es otra forma de ejercicio del poder que, paradójicamente, ha dependido de los Estados como cooperadores necesarios para lograr desbordarlos.

Ya he señalado en la respuesta anterior algunas limitaciones del enfoque neoinstitucionalista. Por descontado, las culturas (también las escolares) no son esencias intemporales grabadas a fuego en un colectivo o institución cerradamente territorializados. Por el contrario, se construyen, se reconstruyen, se hibridan, se disputan y pelean, se violentan, se segmentan, se expanden, se repliegan..., y en esa evolución juegan un papel tanto factores endógenos como -según insisten los 
Raimundo Cuesta y Marta Estellés, Consideraciones críticas sobre la mundialización...

neoinstitucionalistas- exógenos. Ahora bien, la interacción entre unos factores y otros no suele dar lugar a materializaciones y dinámicas únicas ni unívocas. En el caso que nos incumbe, la masificación de ciertos significantes organizativos y curriculares no ha traído consigo que cobren el mismo significado en todas partes. Razón por la cual sería más atinado verlos, en expresión de Tröhler, como significantes flotantes que eventualmente pueden adoptar diferentes concreciones en unos contextos y otros. Por ejemplo, Hajisoteriou y Angelides (2013) evidenciaron recientemente la ostensible influencia de la Unión Europea y de otros organismos internacionales en las políticas educativas chipriotas. Pero también el modo en que esas "políticas globalizadas" resultaban mediadas por los actores nacionales, regionales y locales que participaban en su adopción e implementación, condicionando el resultado e incluso alejándolo de las finalidades anunciadas. Bien entendido que la actuación de estos agentes no se explicaba únicamente en función de sus idiosincrasias culturales, sino también de sus circunstancias materiales, de los elementos habilitantes y constrictivos del ordenamiento institucional, de su posición en la estructura del conflicto político y étnico latente, de la escala espacial en la que se movían, etc. La historia de la escuela no puede leerse sólo desde el plano económico. Tampoco sólo desde el plano cultural. $\mathrm{Ni}$, desde luego, como diré en el siguiente punto, es el fruto de un progreso lineal y acumulativo. Nada más lejos de la realidad.

P.: A menudo, el economicismo atraviesa y desvirtúa el pensamiento crítico. El viraje hacia la escuela entendida como cultura ha sido muy pujante desde los años ochenta. D. Tröhler pone el énfasis en los lenguajes educativos, en tanto que estructuras profundas de representación de los discursos psicopedagógicos dominantes, que, según él, favorecen la pedagogización del mundo conforme a una herencia calvinista, remozada por las ciencias de la educación. Sin embargo, pasa por alto la influencia del capitalismo en el devenir de los sistemas educativos. ¿Cómo interactúan los factores religiosos y los económicos en la evolución de la escuela?

R.: He de reconocer desde un inicio que no sé contestar a semejante pregunta. Sospecho que no tiene una sola respuesta omnicomprensiva y que, en su lugar, deberían buscarse respuestas empíricas en cada caso objeto de estudio. La globalización, sirva el botón de muestra, no ha tenido un efecto idéntico en todos los sistemas políticos (ni, por tanto, en sus medidas educativas), y no sólo por el grado de desarrollo económico del país, sino también por el tipo de instituciones, el tipo de 
Estado de bienestar, la fiscalidad y gasto público, la mejor o peor gobernanza democrática, el nivel e intensidad de crecimiento de la desigualdad, la estructura del conflicto social y político, etc. De igual manera, tampoco los países en los que se deja sentir la herencia calvinista han organizado históricamente sus sistemas educativos y sus curricula de un modo estrictamente paralelo. $Y$ yo no aventuraría que el motivo (en singular) haya sido el mayor o menor peso de las distintas familias del protestantismo calvinista (puritanos, presbiterianos, etc.).

Me parece que los términos de la pregunta descansan en dos presuposiciones discutibles. La primera es el aislamiento de los factores económicos y religiosos. $\mathrm{Ni}$ unos ni otros son fuerzas independientes que caminan solas al margen de lo "demás", ni lo "demás" es un mero epifenómeno. La segunda es una focalización excluyente en el largo plazo, sea económico, cultural o alguna mezcla conveniente de ambos. No se me entienda mal. Como afirmaba Claude Lévi-Strauss, los fenómenos sociales, al igual que algunos alimentos, poseen un "sabor" distinto según el corte que se les practique: acaso en el día a día "sepan" a conductas y motivaciones individuales, pero al ampliar la perspectiva analítica el paladar comienza a advertir los efluvios de la sociología, la economía o la historia; y si se opta por las indagaciones de "larga duración" se llega a captar cómo se han ido "produciendo" y alterando muchos rasgos que se consideraban inscritos en el "orden natural de las cosas". Todos esos cortes son imprescindibles, porque todos esos sabores son constitutivos del fenómeno. Lo es la larga duración, por descontado, para advertir, por ejemplo, la honda impronta religiosa en la ilusión redentora que ha impregnado tan profundamente los "lenguajes educativos". Pero también lo son los restantes "tiempos" históricos.

Nosotros hemos estudiado con cierto detenimiento la transformación de los sistemas educativos duales decimonónicos en los sistemas educativos comparativamente más integrados del siglo XX. Esta transformación, crucial, dista mucho de ser un proceso lineal y armónico. $Y$ no puede entenderse al margen de las mutaciones institucionales que reestructuraron el "orden burgués" en ese largo, incierto, agitado, traumático y dramático proceso, lleno de salidas en falso, que afectó a todo el mundo occidental desde la crisis de los regímenes liberales en las últimas décadas del siglo XIX, que se agudizó tras la Revolución Rusa de 1917 y durante el período de entreguerras, y no alcanzó un punto de estabilidad relativa hasta después de la Segunda Guerra Mundial con la implantación de los Estados del bienestar. El agudo y prolongado conflicto provocado por la desigualdad socioeconómica, el exclusivismo del sistema político y otras líneas de antagonismo según países no 
Raimundo Cuesta y Marta Estellés, Consideraciones críticas sobre la mundialización...

impidió, en el mundo occidental, la persistencia de unas estructuras y unas hegemonías sociales, ni la supervivencia y adaptación de las élites económicas y del sistema capitalista por ellas dominado. Pero la consecución de la estabilidad no pudo hacerse sin crear nuevos ordenamientos institucionales y nuevas formas de distribución del poder en las que ya no fue posible obviar a las masas. Un resultado contingente que la modernización conservadora comenzó a desmontar desde la década de 1980. No hay linealidad en esta historia, ni esta historia puede reducirse a un factor económico y/o religioso, por más que ambos estuviesen presentes.

P.: En España en las últimas décadas impera una neolengua de uso común tanto para gobiernos de izquierda como de derecha (competencias, niveles de rendimiento, estándares de aprendizaje...), que expresa el pacto no escrito sobre la educación y sus metas. ¿Constituye la impugnación de estos lenguajes una precondición del pensamiento crítico en educación? ¿Qué herramientas heurísticas se pueden utilizar para desenmascarar ese consenso universal sobre la escolarización?

R.: En el ámbito mencionado en la pregunta, y en cualquier otro, la reflexión crítica y autocrítica sobre los "actos de habla" -valga la conocida expresión de John L. Austin- debería ser una preocupación básica. Si algo nos han dejado en herencia los denominados "giro lingüístico" y "giro reflexivo" de la teoría social es la necesidad apremiante de objetivar -para poder analizar- los sobrentendidos tácitos del propio lenguaje que utilizamos para designar, atribuir significados a, y tratar de conformar la realidad. No en vano, lo que nos permite articular nuestras percepciones y cogniciones son las convenciones del habla y la red de categorías semánticas intersubjetivas interiorizadas a través de nuestra socialización cultural. Ambas crean los lugares comunes que facultan la comunicación y la interacción. Tales convenciones y categorías habilitan nuestra comprensión y, a la par, dificultan otras miradas excéntricas a las presuposiciones que dan por sentadas. Según señalaba Edgar Morin, "estamos abiertos por el lenguaje, encerrados en el lenguaje, abiertos a los otros por el lenguaje (comunicación), cerrados a los otros por el lenguaje (error, engaño, incomprensión), abiertos a las ideas por el lenguaje, cerrados a las ideas por el lenguaje. Abiertos al mundo y apartados del mundo por nuestro lenguaje". Más aún, como los hechos no se nos representan independientemente de nuestros instrumentos de significación, el lenguaje y la urdimbre conceptual tejida con él pueden co-participar en la constitución misma de la realidad enunciada y pensada. 
Estoy aludiendo, obviamente, al impacto performativo del lenguaje: cabría decir, parafraseando a Judith Butler, que las palabras pueden no solo nombrar sino también, en cierto sentido, realizar lo que nombran. Por tal motivo, se me antoja acuciante aprender a dudar de las prácticas discursivas que modelan nuestras subjetividades a fin de vislumbrar cómo nos enredan, a menudo de manera inconsciente, en los procesos más amplios de producción y reproducción social.

Sin embargo, no es nada sencillo alcanzar suficiente distancia para ver, no sólo el mundo, sino a nosotros mismos viendo el mundo, y poner en entredicho nuestro modo de ver. Una manera prometedora de acercarse a esa "reflexividad" es la "historización" de los usos del lenguaje, de las formaciones conceptuales y las consiguientes tramas narrativas. No me refiero a la clásica historia lineal de las ideas, a menudo teleológica, sino a los análisis de las variaciones semánticas y los neologismos en relación con las bases institucionales de esas nociones y con las condiciones de su devenir en el tiempo, con vistas a desvelar su naturaleza socialmente construida. En un sentido más general, me refiero igualmente a cualquier historia genealógica que problematice el "mundo axiomatizado", nuestras certezas de sentido común, y que contribuya a extrañar o des-familiarizar los "regímenes de verdad" subyacentes (en tanto que estructuras estructuradas y, a la vez, estructurantes de nuestros pensamientos y prácticas).

Pues bien, centrándonos en el tema concreto de la pregunta, me parece evidente que los nuevos estilos de gobernanza y gestión empresarial de colegios e institutos se apoyan en un peculiar relato del cambio social -con su diagnosis, prognosis y misión de futuro- que pretende imponerse como "régimen de verdad". Es dentro de ese marco desde el que se ha promocionado la organización por competencias como flamante receta curricular para la escuela del siglo XXI. Reconozco que su ambigua polisemia me suscita una profunda ambivalencia. Aunque el enfoque de las competencias tiene su origen en el ámbito de la formación profesional u ocupacional, ciertamente ha ido agrandando su radio hasta presentarse como "solución" para todo el curriculum. Aparentemente, además, su énfasis en la movilización de los saberes, en la funcionalidad de los aprendizajes, en la imprescindible conjugación de distintos tipos de conocimientos (conceptuales, factuales, destrezas cognitivas, habilidades procedimentales, actitudes, valores, emociones) o, por resumir, en la noción de una "educación para la vida" enlaza con venerables tradiciones innovadoras y con principios didácticos loables que comparto. Mi prevención no surge entonces del significado potencial que puede alcanzar el término "competencia", sin duda muy 
Raimundo Cuesta y Marta Estellés, Consideraciones críticas sobre la mundialización...

amplio, sino del sesgo efectivo que le han insuflado sus patrocinadores orgánicos. El problema es que ese sesgo suele quedar velado por el dualismo superficial que ha presidido el debate, reducido en su presentación a un enfrentamiento entre las necesidades del presente y del futuro, por un lado, y el lastre de un pasado representado por el vetusto academicismo, por otro. Semejante dualismo miope y desmemoriado pasa por alto que la buena nueva competencial no es sino la actual variación melódica de una música añeja, y que su encumbramiento ignora o silencia otras perspectivas curriculares con un rico y dilatado bagaje a sus espaldas. Si prestásemos más atención a las investigaciones realizadas en el campo de la historia del curriculum, hubiésemos advertido que, frente a ese academicismo, la alternativa de una educación funcional para la vida ha sido interpretada y practicada de maneras muy diferentes por tradiciones rivales. Desde el "aprender haciendo" al modo paidocéntrico, puesto al servicio del desarrollo psicoafectivo "natural" de un niño igualmente "natural" en realidad inexistente; hasta el "utilitarismo adaptativo" de los eficientistas deseosos de preparar a los niños para el correcto desempeño de unos futuros roles laborales y sociales que se dan por sentados; pasando por quienes desde hace un siglo vienen defendiendo un uso democrático del conocimiento encaminado a la resolución inteligente de los asuntos públicos controvertidos, como forma de actuar desde el curriculum contra las desigualdades e injusticias sociales y en favor de una cultura cívica sólida. Pues bien, si hay una inclinación preponderante en la literatura oficial sobre las competencias, no es otra que la de ese "utilitarismo adaptativo" que conmina a prepararse para un amoldamiento eficaz a exigencias o circunstancias que se dan por naturales o inevitables y que, por tanto, se escamotean de la discusión. Aunque metamos en el saco las "competencias cívicas", si la democracia implica la producción social consciente de las normas e instituciones colectivas, una educación para la democracia no puede ser meramente "adaptativa".

Pero es que, además, las competencias no han llegado solas, sino de la mano de nuevas políticas educativas que redefinen el concepto de mejora desde una óptica productivista, en torno a la consecución de resultados o indicadores medibles, y que aplican a la escuela los principios gerencialistas de la new public management, con la consiguiente obsesión por los rendimientos discentes y la rendición de cuentas mediante evaluaciones externas estandarizadas, etc. Hasta el extremo de que, por ejemplo, en nuestras evaluaciones generales de diagnóstico y en las pruebas internacionales de la IEA se determinan "niveles de rendimiento" en la adquisición de la "competencia ciudadana". Estos usos del lenguaje desconciertan. Y son peligrosos, 
pues entrañan una visión apolítica de la ciudadanía y una concepción técnicoinstrumental de la vida pública en las cuales la pasividad cívica, al igual que el riesgo de exclusión, se tiñen de tintes auto-inculpatorios y se individualizan. Pero no nos quedemos únicamente en el ejemplo. En aquellas latitudes donde estas evaluaciones externas de estándares están teniendo consecuencias (en la diferenciación de los colegios y la segmentación de sus "clientelas", en la financiación de los centros, en el salario de los profesores..., su implantación ha acarreado efectos perversos para la equidad y para la misma aspiración de una educación democrática, evidenciados desde hace tiempo por la investigación empírica.

P.: Hoy en día las burocracias de los organismos internacionales juegan un papel creciente en la homogeneización escolar. ¿Hasta qué grado esta tecnoburocracia educativa funciona como un Estado dentro del Estado? ¿Existe una coalición multinacional entre la razón burocrática y el interés empresarial a favor de esa uniformización?

R.: Yo no hablaría de un "Estado dentro del Estado" porque suena demasiado conspirativo y porque, en mi humilde opinión, no refleja adecuadamente las dinámicas que nos envuelven. Intentaré explicarme con un rodeo por el que pido disculpas. Empleando la terminología de Giddens, podría decirse que las propiedades estructurales y los ordenamientos institucionales de toda sociedad se despliegan por un espacio y un tiempo, a través de mecanismos de integración y reproducción sociales. Pues bien, debido a la magnitud de las transformaciones asociadas a la modernidad y al dominio económico, político, tecnológico y militar de Occidente, los modos de organización colectiva surgidos inicialmente en Europa a partir del siglo XVIII, para impactar con posterioridad en el resto del orbe, comenzaron a "estirar" su influencia a una escala desconocida, que no ha dejado de agrandarse desde entonces a pesar de su compleja relación con los elementos de perduración y resistencia. En lo concerniente a su extensión, estos cambios han traído aparejado el establecimiento de interconexiones de alcance planetario; en lo concerniente a su intensidad, tales cambios han llegado a las esferas más íntimas de nuestra cotidianidad. Una consecuencia trascendental ha sido la incidencia cada vez mayor de las circunstancias separadas de las interacciones "cara a cara"; esto es, la gradual dislocación de espacio y lugar. A resultas de ello, los aspectos locales se ven afectados en profundidad, y a veces conformados, por influencias sociales distantes 
Raimundo Cuesta y Marta Estellés, Consideraciones críticas sobre la mundialización...

que pasan a integrarse en el aquí y el ahora. Se han alumbrado así instituciones "desancladas" que engarzan las prácticas acostumbradas en un territorio con esas relaciones más generales. Desde esta óptica, Giddens interpretó la globalización actual como una radicalización de la modernidad, que dista mucho de brotar ex novo, aunque suponga un salto cualitativo en esta espiral. Porque ciertamente la globalización no se reduce a la nueva economía electrónica transnacional, sino que es además política, tecnológica y cultural. Porque, pese a denotar el poderío de las potencias mundiales y resultar profundamente desigual en sus efectos, no es sólo hegemonía de los países ricos sobre el resto, sino que influye también en los primeros. Porque afecta a múltiples facetas y no tiene que ver sólo con lo que está "ahí fuera", sino también con el "aquí dentro". Porque está transformando la organización del espacio: si, según Castells, la "sociedad red" es la nueva estructura social dominante a nivel mundial, el "espacio de flujos" sería su correlato, sobresaliendo por encima de las demás formas y procesos espaciales.

Pues bien, el hecho de que nuestras circunstancias acusen de forma creciente la fuerza estructuradora de las dinámicas transterritoriales, y el hecho de que las principales redes de poder se alineen ya en ese espacio de flujos son factores que han contribuido a transformar las perspectivas de las comunidades políticas. Siguiendo a David Held podría decirse que: 1) ya no cabe identificar sin más el lugar del poder político efectivo con el gobierno nacional. El poder efectivo es compartido y pactado por agentes e instituciones diversos en los niveles estatal, regional e internacional; 2) el principio de autodeterminación en sentido político no puede ya ubicarse dentro de los límites de una sola nación-Estado, toda vez que algunas de los procesos más determinantes en la definición de nuestras oportunidades de vida rebasan sus fronteras privativas; 3 ) el hecho de que el Estado deba operar dentro de sistemas regionales y globales complejos incide tanto en su autonomía como en ciertas dimensiones de su soberanía; y 4) la distinción entre asuntos domésticos y extranjeros queda en entredicho por la irrupción de toda una serie de agendas y problemas transfronterizos.

En mi opinión, las políticas educativas actuales reflejan claramente esta realidad. Es más, me atrevería a afirmar que las administraciones educativas de los países son buenos ejemplos de "instituciones desancladas": hace mucho tiempo que no producen discurso propio, sino que se limitan -con mejor o peor tino, con mayor o menor creatividad, con un filtro de un color u otro- a tratar de "re-anclar" las agendas globales a las condiciones particulares de su jurisdicción. Y en esa labor no sólo juegan un 
Raimundo Cuesta y Marta Estellés, Consideraciones críticas sobre la mundialización...

papel "la razón burocrática y el interés empresarial". Otro actor importante proviene del mundo académico, internamente muy diverso: un sector se mueve con comodidad en el "espacio de flujos", mientras que otro apenas va más allá del "espacio de lugares". Algunos representantes del primer sector participan en la elaboración de los informes, propuestas y recomendaciones de los organismos internacionales. Algunos representantes del segundo asumen con entusiasmo el rol de voceros a nivel local. EI problema obvio es que esta suerte de proceso en cascada dista mucho de ser democrático: instancias supranacionales, en buena medida exentas de los habituales mecanismos de responsabilidad ante la sociedad civil, se erigen en "intérpretes del futuro inevitable" e imponen una suerte de ideología de la adaptación que hurta al debate público sus apuestas programáticas, ocultas bajo el diagnóstico aparentemente aséptico de los desafíos venideros.

P.: Fedicaria, el grupo editor de esta revista, es una plataforma de pensamiento crítico de profesores y profesoras que pugnan con los poderes al servicio de la mercantilización y homogeneización del conocimiento. En tu contexto profesional, ¿imaginas alguna práctica colectiva más allá del trabajo académico individual?

R.: Al terminar mi Licenciatura en Historia, yo tuve la enorme fortuna de iniciarme en la reflexión, la investigación y la práctica educativas de la mano del grupo Asklepios, un colectivo de docentes de distintas etapas y de doctorandos dirigido desde la Universidad de Cantabria por el profesor Alberto Luis Gómez. Y de formarme en los densos seminarios -sentidamente añorados- que este grupo celebraba con bastante frecuencia. Tales seminarios fueron mi experiencia vital más próxima al horizonte deseable, expresado hace ya mucho por E. P. Thompson, de espacios colectivos donde discutir en profundidad, sin concesiones ni ataduras, donde ayudarse con camaradería y donde, al mismo tiempo, criticarse mutuamente. En este sentido, el funcionamiento interno del grupo Asklepios tuvo su continuidad natural en Fedicaria, en la cual se integraba. No podría reconocer mi pensamiento al margen de esa riquísima doble impronta.

El sistema de estímulos que impera hoy en la Universidad no propicia este tipo de dinámicas. En España hay quien habla de la progresiva generalización de una "cultura ANECA", en alusión a la agencia nacional que otorga las acreditaciones de la carrera académica. El tropo no es del todo impertinente, pues nos recuerda cómo la lógica institucional ahorma las conductas. En este caso, las reglas de juego de la 
Raimundo Cuesta y Marta Estellés, Consideraciones críticas sobre la mundialización...

ANECA han tenido distintos efectos. Algunos sin duda positivos. $Y$ otros contraproducentes, al acentuar, entre otras cosas, el rechazo de cualquier actividad que no tenga una recompensa prosaica individual e inmediata.

Sin embargo, la acción colectiva es más urgente que nunca. Más aún: dado el panorama de destinos solapados que pintaba en mi anterior respuesta, lo urgente es crear redes de cooperación a través de las fronteras que permitan coordinar respuestas. No es nada fácil, pero ese reto me parece insoslayable.

\section{CONTRIBUCIÓN AL DEBATE SOBRE LA MUNDIALIZACIÓN DE LOS SISTEMAS EDUCATIVOS DE... INÉS DUSSEL}

Pregunta: Después de cuatro décadas de enfoques historiográficos inclinados hacia lo microhistórico y lo cultural, en la actualidad se aprecia una resurrección de las perspectivas, como la Global History, que reclaman una visión sinóptica y una temporalidad de larga duración. ¿Hasta qué punto en la historia del curriculum y de la Pedagogía se está produciendo un giro "global" de las investigaciones?

Respuesta: Creo que ese giro global, aunque existe, es todavía incipiente, y tiene que ver con el trabajo que se está haciendo desde distintas instituciones y sociedades (destaco a la ISCHE, International Standing Conference for the History of Education, entre ellas), que intentan promover una mirada que supere el "nacionalismo metodológico", como lo llamaron los investigadores alemanes Andreas Wimmer y Nina Glick Schiller. Sin embargo, lo primero que resaltaría es que buena parte de la investigación en historia de la educación sigue estando anclada en las fronteras nacionales, y sigue sosteniendo los relatos históricos fundantes de los estados nacionales de fines del siglo XIX. En los años noventa hubo un giro hacia lo local, lo microhistórico, muchas veces entendido como una pieza de un rompecabezas más grande: la nación. Entonces me parece que el giro global está llegando, pero de a poco, y en general de la mano de historiadores que se mueven en ciertos circuitos de congresos, publicaciones y estancias internacionales. La mayor parte de la historia de la educación (sobre todo la que se enseña -cuando se enseña- en la formación docente) tiene todavía un marcado sesgo nacionalista.

Lo segundo que diría es que en la pregunta están implícitas dos cuestiones que podemos analizar con más detalle. Por un lado, diferenciaría la historia del curriculum de la de la pedagogía, no desde un cierto purismo terminológico sino porque creo que 
es importante reconocer que hay discusiones historiográficas específicas, que se vinculan al objeto o materia que se investiga. Tomemos el caso de la primera: el curriculum suele ser un documento nacional, aunque cada vez se lo piensa más como un marco de acuerdos básicos abierto a una especificación en las distintas escalas educativas (las provincias o estados, los distritos escolares, las modalidades, los establecimientos escolares). Sin embargo, la historia del curriculum sigue, en buena parte, apegada a estudiar la trayectoria de las regulaciones del estado-nación, aun cuando mire la escala micro. Pero hay desarrollos nuevos. Destacaría sobre todo la historia de las disciplinas escolares, que en muchos casos la están haciendo los herederos (no siempre conscientes ni declarados) de la ruptura que planteó Michel Foucault. ¿Cuál fue esa ruptura? La perspectiva foucaultiana introdujo una periodización y un corte diferente en la historia de los saberes, que los vinculó a transformaciones epistémicas y políticas, dándole visibilidad a la dimensión materialinstitucional. En esos estudios a veces sigue implícita la misma escala nacional, pero diría que otras veces esa escala es genuinamente desbordada por consideraciones que avanzan más allá y más acá del estado-nación, estudiando cómo se concreta el documento curricular en la micropolítica escolar o analizando la circulación internacional del conocimiento y de las tecnologías escolares (por ejemplo, el examen escrito, que los Jesuitas conocen en China) que tienen actores o portadores no estrictamente nacionales. Diría que ese movimiento habla de un giro global en la historia del curriculum, pero ese giro no toma la perspectiva neoinstitucionalista. Estos historiadores están mirando la transferencia de saberes, portados por distintos agentes (usando la categoría latouriana) que incluyen actores o sujetos humanos y otros no humanos (mapas, bancos escolares, pizarrones, tratados didácticos, documentos, soportes tecnológicos, entre muchos otros). En esta línea incluyo a quienes están trabajando sobre la historia de la materialidad de los documentos curriculares; por ejemplo, algunos colegas británicos investigan los modos en que los documentos llegaron a las escuelas (en papel o en pdf, y sus diseños), y estudian los modos en que fueron leídos y transformados en ellas.

Pensando en la materialidad del curriculum y también de los documentos pedagógicos, otro ejemplo -que vale la pena recordar en el 100 aniversario de su creación- es la historia del Manifiesto de la Bauhaus, redactado y después revisado varias veces por Walter Gropius, pero que fue tipeado por su esposa Ise en una máquina de escribir que era todo un símbolo de modernidad en la época. En esa "pequeña" historia tenemos cuestiones de género, tecnologías, idearios pedagógicos, 
Raimundo Cuesta y Marta Estellés, Consideraciones críticas sobre la mundialización...

cambios políticos. Este manifiesto por una nueva educación artística pasó de ser un panfleto que llamaba al combate político y cultural a convertirse en una pieza de museo; la historiadora Karen Koehler está estudiando sus distintas versiones, y ella destaca que en 1938 el documento se exhibe en el MoMA en Nueva York -con Gropius ya en el exilio- ampliado y enmarcado, sin los signos de exclamación, desprovisto de ese carácter de literatura callejera y llamado a la acción. En el MoMa el Manifiesto ya es un icono: deja de ser un documento de la renovación pedagógica asociado a una institución que quería romper con los moldes del curriculum y la enseñanza y se convierte en una "marca" del circuito del arte y del diseño. Como muestra esta historia, el marco nacional no es el único que explica estas transformaciones, sino que hay que prestarle atención a las redes en que se inscriben los artefactos, esto es, a cómo los saberes se materializan en objetos precisos, viajan y se transforman en espacios y en contextos políticos e institucionales diferentes. Me parece que en esos ejemplos hay evidencias de que hoy se están produciendo nuevas historias de la educación, que miran otros campos, otras trayectorias, con preguntas distintas a las de hace unos años.

Por otro lado, hay una segunda dirección implícita en la pregunta, y es que la escala de lo global equivale a un gran relato o a producir visiones sinópticas sobre lo educativo de larga duración. Me parece que estas nuevas historias del curriculum y la pedagogía lo que hacen no es proveer nuevos grandes relatos sino que ponen en movimiento a lo educativo, lo complejizan, reorganizan sus espacios y sus formas de concretarse en acciones, sujetos y objetos, y también reorganizan las temporalidades, que emergen como más plurales de lo que se pensaba. La cuestión de las temporalidades me parece muy relevante; no es que hay dos direcciones, una hacia delante (la global) y otra retardataria (la nacional o la local), sino que hay temporalidades múltiples, que conectan el pasado, el presente y el futuro de distintas maneras. En los temas que estoy estudiando actualmente -la historia de los medios y las tecnologías visuales en la educación-, es claro que la fotografía introduce una ruptura importantísima, al dejar "impreso" o capturar un momento en la historia que puede ser recuperado en otro momento y en otro espacio, ruptura que el cine profundiza al poner a esos registros en movimiento. Cambian los archivos o registros de la memoria pero también cambia la memoria histórica; no por nada decía Susan Sontag que con la difusión de la foto, el cine y la televisión, recordar es cada vez más recordar imágenes. Esta es una duración mucho más larga que la que estudian los neoinstitucionalistas: son cambios en las tecnologías de escrituración o registro de la 
Raimundo Cuesta y Marta Estellés, Consideraciones críticas sobre la mundialización...

experiencia humana que llevaron siglos, cuando no milenios, y que hoy están transformándose aceleradamente. Esto obliga a repensar las coordenadas de tiempo y espacio, que ya no se pueden pensar como los a priori kantianos sino que hay que reconocerlos como dimensiones de la experiencia humana construidas en entornos políticos y socio-técnicos.

Se abren entonces preguntas sobre qué es una visión sinóptica o de larga duración de la educación, y también sobre las escalas y los grandes relatos. Investigar sobre las tecnologías en educación, ¿es una historia local o global?, ¿es de corta o larga duración? En la medida en que se estudia una tecnología "global" como la cámara, diría que no es microhistórico, pero si estudio un episodio determinado me inclino a pensar que sí lo es. Pero ahí es donde creo que hay que replantear el argumento: como dicen los antropólogos, en el fondo cualquier estudio es un estudio de lo local, de una escala determinada que, si se quiere hacer bien, tiene que llegar a un nivel de detalle y complejidad que permita entender la especificidad del fenómeno que se está estudiando, ya sea la OCDE como nuevo regulador de la educación o un material de enseñanza de la lengua usado en Andalucía en la década de 1850. Una no es necesariamente más local que la otra: depende de qué preguntas o desde qué problemas me acerco a esa escala y a ese problema. En relación con eso, estoy convencida de que es desde ese estudio de la diferencia y la especificidad histórica desde donde podemos aportar a visiones sinópticas y de larga duración de la educación que no nieguen la complejidad y que no abonen a un neo-colonialismo que elimina las diferencias y las desigualdades. La historia del Manifiesto de la Bauhaus permite rastrear algunos hilos centrales del siglo $\mathrm{XX}$ como son los cambios en las relaciones de género, las tecnologías, la mercantilización de la cultura y la educación, los avatares de la promesa democrática, los exilios. ¿Quién puede sostener que no es global, o que no es una punta de entrada relevante para entender las transformaciones de nuestra época?

P.: Si se nos permite efectuar un ejercicio de máxima simplificación, los estudiosos del tema de la mundialización educativa podrían dividirse en dos grandes categorías enfrentadas: economicistas y culturalistas. Entre los primeros, se encuentran los teóricos del capital humano y de la educación como inversión productiva, así como las teorías marxistas que consideran la expansión mundial de las escuelas como un epifenómeno del capitalismo. Frente a ambas, algunas posiciones culturalistas neoweberianas, como las de la sociología neoinstitucionalista, 
Raimundo Cuesta y Marta Estellés, Consideraciones críticas sobre la mundialización...

consideran la educación como un ideal compartido y una forma de legitimación del poder gubernamental. ¿Qué tipo de perspectiva te parece más interesante? ¿Es posible superar estos marcos interpretativos?

R.: Me parece que en los desarrollos que mencionaba antes, la dicotomía economía-cultura está siendo superada. La cultura tiene una dimensión material y económica innegable; mirar cuánto costaban los libros, cuadernos o uniformes es parte fundamental de entender qué se pudo difundir y qué se mantuvo como privilegio o directamente no prosperó como vehículo de ciertas transformaciones. De la misma manera, insistir en que la obligatoriedad escolar tiene un costo y un beneficio económico para las sociedades -que es mucho más complejo que la tasa de retorno de la teoría del capital humano- me parece fundamental. Los historiadores culturales (entre los que me incluyo) a veces tenemos una ingenuidad imperdonable en pensar que las ideas o las costumbres circulan sueltas, solas, por su propia fuerza, sin pensar en cómo lo hicieron, cuánto costaba, en muchos sentidos, esa circulación, qué hacía la gente para vivir o sobrevivir, y más en concreto de qué vivían los maestros, qué condiciones de trabajo concretas tenían, lo mismo que los alumnos y sus familias. Por supuesto, eso no explica todo; ahí es donde el determinismo no ayuda, pero no ayuda en ninguno de los casos. Siempre hay una variedad de dimensiones que se conjugan de maneras muy específicas en cualquier situación histórica. ¿Cuáles son las que tienen más peso o más fuerza? Me parece que esa tiene que ser una pregunta empírica, que hay que responder en un contexto situado.

Más en concreto sobre el neoinstitucionalismo, creo que esta corriente hace aportes interesantes, pero muchas veces sus aproximaciones me parecen de un nivel de generalidad excesivo. Prefiero la perspectiva del filósofo francés Bruno Latour, o una adaptación con matices de sus supuestos epistémicos y metodológicos. Los latourianos analizan las trayectorias de agentes que operan en redes que pueden ensamblarse de manera provisoria en algunas configuraciones más o menos estables, y ese ensamblado requiere trabajo de los agentes. Si efectivamente el ideal educativo se difundió por el mundo, en distintos contextos, entonces eso quiere decir que viajó a través de ciertos conectores o portadores que hay que estudiar, y logró armar una red supranacional que antes no existía, o no existía de esa manera. ¿Qué hizo a la escuela graduada un modelo exitoso de escolarización en lugares tan diversos como Alemania, Estados Unidos, India, Argentina o África subsahariana? ¿Fue solamente el colonialismo europeo, o quizás es un modelo o idea que se convirtió en un vector 
Raimundo Cuesta y Marta Estellés, Consideraciones críticas sobre la mundialización...

que permitía reorganizar el trabajo educativo y las estrategias de ciudadanización en distintos contextos? En México la escuela graduada entra más tarde, y todavía hoy subsiste una cantidad importante de escuelas rurales que negocian entre el plurigrado y el grado único. De nuevo, me parece que hay que basarse en investigaciones concretas que muestren cómo ese modelo fue avanzando, quiénes lo impulsaron, qué recursos tenían o pudieron movilizar, y qué formas adquirió en cada lugar. Y también prestar atención al hecho de que a veces las mismas palabras (como educación o escuela) tienen sentidos muy distintos en diferentes contextos. Para entender 0 explicar esas diferencias, el neoinstitucionalismo no me resulta útil; me parece más interesante la antropología histórica de la escuela, que no renuncia a miradas de conjunto, pero tampoco a atender la singularidad de los procesos de escolarización en cada contexto.

P.: A menudo, el economicismo atraviesa y desvirtúa el pensamiento crítico. El viraje hacia la escuela entendida como cultura ha sido muy pujante desde los años ochenta. D. Tröhler pone el énfasis en los lenguajes educativos, en tanto que estructuras profundas de representación de los discursos psicopedagógicos dominantes, que, según él, favorecen la pedagogización del mundo conforme a una herencia calvinista, remozada por las ciencias de la educación. Sin embargo, pasa por alto la influencia del capitalismo en el devenir de los sistemas educativos. ¿Cómo interactúan los factores religiosos y los económicos en la evolución de la escuela?

R.: Es una pregunta compleja, a la que intentaré responder con dos o tres reflexiones. En primer lugar, para pensar en estos procesos prefiero los abordajes foucaultianos, que priorizan la lectura política en todas las dimensiones (lo económico o lo religioso serían ante todo configuraciones de poder, con sus enunciados o formas de regulación específicas pero que pueden ser estudiadas con un lente similar), o bien los latourianos, que no dan por sentado qué aspecto se reconoce como económico o político. Ambas perspectivas tienen puntos de conexión; de hecho, Foucault, en el volumen 2 de su Historia de la sexualidad, analiza la economía en la tradición griega que engloba un saber sobre el espacio doméstico y sobre las relaciones conyugales. Es decir, lo que englobamos dentro de un pensamiento o dimensión económica va cambiando con el tiempo y con la reconfiguración de los saberes sobre las prácticas sociales, y también con los desarrollos institucionales (la especialización disciplinaria, por ejemplo), entre muchos otros aspectos; lo mismo puede decirse de lo religioso, 
Raimundo Cuesta y Marta Estellés, Consideraciones críticas sobre la mundialización...

que tendemos a pensar con las claves del estado secular del siglo XIX y XX, que son claves que más bien habría que problematizar -lo que hace muy bien Daniel Tröhler. Pensar que hay una dimensión económica y otra religiosa que se definen por sí mismas, fuera de la historia y de sus relaciones con otras dinámicas, y que son idénticas en todo lugar me parece equivocado.

En segundo lugar, la interacción de factores me parece que hay que situarla en la historia: ¿cómo se combinaban los factores religiosos y los económicos, entendidos de manera específica y situada, en la escolarización en contextos particulares? Pensando en este tema, me acordé de un trabajo de hace unas décadas de un crítico cultural brasileño, Roberto Schwarz, que hablaba del liberalismo brasileño como una "idea fuera de lugar", apuntando que los liberales habían trasplantado una retórica política que suponía sujetos muy distintos a los que existían en Brasil en ese momento. Este concepto generó mucho debate (¿acaso hay "un” lugar al que pertenezcan las ideas?), pero es una buena advertencia de que los programas o discursos sobre la escolarización se transforman, desplazan y asumen otros sentidos en su circulación en distintos contextos. Los "factores económicos" claramente son muy distintos en Brasil en el siglo XIX, con una economía todavía esclavista, azucarera o cafetera, con remanentes de la minería colonial, con una proto-industrialización en el sur, que en la Suiza del siglo XIX que tiene una estructuración productiva de otro orden. $Y$ sin embargo en ese siglo los pedagogos suizos y brasileños leen a Pestalozzi y creen que hay que escolarizar a la infancia; en eso se ve una idea que viajó y tuvo éxito en distintos contextos. El tema, creo, son cuáles son los sujetos que encarnan estos programas, las estrategias que desarrollan, las instituciones que crean, la trama discursiva, económica y política en la que esa idea "cobra vida", por así decirlo. No es tan sencillo como que los fazendeiros necesitaban o no necesitaban una población alfabetizada, o que el estado quería pelearle el dominio político a los católicos; me parece que es mucho más complejo que eso.

En tercer lugar, la cuestión de lo religioso se entreteje con otras dimensiones, pero admito que no es algo que haya estudiado con cuidado, probablemente porque, como dice Marcelo Caruso, para quienes nos formamos en las instituciones herederas del estado laico del siglo XIX la religión es un punto ciego, nos cuesta mirarla como una dimensión constitutiva de lo social. El trabajo de Daniel Tröhler me parece productivo para problematizar la continuidad de una dimensión religiosa en la escolarización, de las formas de pensar el vínculo pedagógico y los ideales formativos, de la misma manera que me parece importante tomar la noción de poder pastoral de 
Foucault, con obvias huellas weberianas. Creo que el pastoralismo es un gran tema en la historia de la pedagogía, y los trabajos de Tom Popkewitz han sido fundamentales para visibilizar la continuidad de la redención y la salvación en los programas educativos laicos. También hay mucho para pensar sobre la conjunción del capitalismo actual con el espiritualismo new age y la auto-superación personal; economía y religión van bastante de la mano en muchos casos.

Lo que en cualquier caso diría es que hay que evitar los determinismos, y también las posturas que dan por sentado que lo económico o lo religioso son unos procesos o sujetos independientes o desgajados de otros. Doy otro ejemplo. En Argentina se dio una discusión en los años setenta sobre la primacía de la variable política sobre la económica en el desarrollo de la escolarización. El argumento, promovido sobre todo por Juan Carlos Tedesco (2005), era que la escuela de fines del siglo XIX tuvo el fin de formar ciudadanos pero que el nivel de desarrollo capitalista no necesitaba la formación de una fuerza de trabajo escolarizada; el debate era sobre todo con las hipótesis del capital humano y también con los althusserianos, y la intención era darle cierta autonomía a la escuela, reconocer su potencial democrático. Si bien estoy de acuerdo con esa intención, creo, como lo debatí con Tedesco en su momento, que no hay por qué aceptar que lo económico es esa versión reduccionista del marxismo de un ajuste perfecto entre fuerzas productivas e instituciones culturales; también hay que revisar ese funcionalismo de buscar la función predefinida que la escuela supuestamente ejecuta (algo así como un principio teórico-político que se despliega hegelianamente en la historia, como bien lo criticó lan Hunter). En ese contexto, hay otros marxismos, como el de Raymond Williams, que me parecen más interesantes para pensar los vínculos entre cultura y economía. Pero con el tiempo me gustan más otras perspectivas (el postestructuralismo, o las lecturas benjaminianas sobre la cultura y la experiencia) para abordar la historia de la escolarización, que piensan las ideas y las prácticas pedagógicas desde una perspectiva materialista.

P.: En España en las últimas décadas impera una neolengua de uso común tanto para gobiernos de izquierda como de derecha (competencias, niveles de rendimiento, estándares de aprendizaje...), que expresa el pacto no escrito sobre la educación y sus metas. ¿Constituye la impugnación de estos lenguajes una precondición del pensamiento crítico en educación? ¿Qué herramientas heurísticas se pueden utilizar para desenmascarar ese consenso universal sobre la escolarización? 
R.: Coincido en la primacía de las ideologías consensualistas a un cierto nivel, pero también hay que estar atentos a los discursos polarizadores de la extrema derecha que ya no quieren entenderse con nadie y que quieren imponer sus propuestas por la fuerza (el gobierno de Trump es un claro ejemplo de eso). Al mismo tiempo, desde América Latina tuvimos y tenemos la experiencia de gobiernos populares de izquierda que también apelaron a una gran polarización; en Argentina se habla de "la grieta" entre los kirchneristas y los anti-kirchneristas, algo que en México se está replicando con la oposición entre los "fifís" y el "pueblo" en el contexto actual. Es una manifestación distinta pero quizás con parentescos con lo que se vive en países donde gobierna la ultraderecha: el consenso no parece estar en alza. En ese contexto, es importante buscar algunos modos de entendernos o vivir en común, sin que eso implique asumir la visión pos-política de que todo es consenso y armonía. Pero me gusta lo que dice Latour: vivimos en una época iconoclasta, más cerca de quemar monumentos que de erigirlos. Quizás sea más interesante e irreverente preguntarse por ese gesto, y suspenderlo por un rato, a ver qué se produce.

Dicho esto, no es que creo que haya que suspender la actividad crítica, pero la actividad crítica no es igual a sacar el hacha y destrozar todo sino que es, como decía Foucault, tratar de hacer tajos en lo que creemos que sabemos, pensar si las cosas pueden ser de otro modo. Pensando en la neolengua de la que hablan, que coincido que es un obstáculo para el pensamiento crítico, creo que es urgente impugnar su discurso anti-escolar, su desprecio por los tiempos y espacios del trabajo de la escuela. Ese trabajo consiste en ofrecer lenguajes y experiencias del mundo con un horizonte de un "para todos", una idea de lo común. Me gusta mucho el trabajo de Jan Masschelein, Gert Biesta y Jorge Larrosa, que denuncian el desplazamiento de la pedagogía hacia el discurso del aprendizaje, con consecuencias nefastas para la escuela y la enseñanza. Eso no quiere decir que no importa qué se aprende; quiere decir resistirse a la subsunción de lo educativo dentro de la lógica productivista y maquínica del capitalismo actual. Hay que pelear por que la escuela pueda hacer ese trabajo de presentar el mundo a las nuevas generaciones sin la presión de acomodarse a los estándares de rendimiento inmediatos de otras esferas. ¿Esto quiere decir que se haga cualquier cosa? No, pero, si vamos a evaluar lo que hace, tendríamos que pensar en efectos que tienen plazos no inmediatos, y sobre todo poner en el centro la preocupación por cuál es el mundo común que se está construyendo con la experiencia escolar, y cómo se está equipando a las nuevas generaciones para 
Raimundo Cuesta y Marta Estellés, Consideraciones críticas sobre la mundialización...

actuar en él. Es un tema bien amplio, que solamente puedo esbozar aquí, pero el eje de la crítica creo que tendría que ir por ese lado.

P.: Hoy en día las burocracias de los organismos internacionales juegan un papel creciente en la homogeneización escolar. ¿Hasta qué grado esta tecnoburocracia educativa funciona como un Estado dentro del Estado? ¿Existe una coalición multinacional entre la razón burocrática y el interés empresarial a favor de esa uniformización?

R.: Creo que hay que estudiar a esa tecnoburocracia con los ojos de los antropólogos y los historiadores. ¿Qué razones y qué trayectorias se instauran como las globales en esos grupos? ¿Cómo fueron cambiando? Son supra-estados, más que estados dentro del estado; en ocasiones son también burocracias anti-estatales, y ahí se juntan con algunos sectores capitalistas concentrados que ven en el estado un obstáculo para su crecimiento. Por todo eso, me parece que no hay que dar por sentado que las tecnoburocracias de la OCDE, la Unión Europea, el Banco Mundial o el FMI son los mejores o los únicos representantes de lo global; por ese camino, medio sin darse cuenta, se termina aliado con la ultraderecha en su visión nostálgica, racista y aislacionista. El aislacionismo no es buena salida para los problemas sociales y planetarios actuales; al revés, creo que hay que construir coaliciones globales en las luchas ecológicas y democráticas, pero de otro orden, impulsadas por otros sujetos y con otros programas.

Al mismo tiempo, pensando en lo que estudio sobre los medios digitales y los procesos de transformación tan rápidos que están teniendo lugar, me pregunto si dentro de poco esa tecnoburocracia va a ser igualmente desplazada. ¿Les interesa a Facebook o a Google que los sistemas educativos sigan los parámetros de la OCDE? Whastapp funciona con un puñado de ingenieros que diseñan los algoritmos (algunos hablan de sólo 50 diseñadores de primer nivel); para volver a la pregunta anterior, sus "necesidades" de formación de la fuerza de trabajo son mínimas. Las plataformas digitales requieren que todos sepamos leer y escribir, pero incluso eso pronto puede llegar a ser reemplazado con las grabaciones de voces e imágenes. O más bien ya está pasando: los estudiantes en las escuelas estudian cada vez más con videos. Podemos argumentar que no es lo mismo leer un texto que escuchar una conferencia, que cada material promueve operaciones distintas con los signos, que la lectura y la escritura permiten una mediación y una reflexión con otros tiempos, más pausados y 
Raimundo Cuesta y Marta Estellés, Consideraciones críticas sobre la mundialización...

distantes; pero por ahí las próximas generaciones ya no tendrán profesores que insistan en eso y toda la educación se desplaza en esa dirección. Dice Éric Sadin, un filósofo francés, que la escena temida de que las máquinas nos dominen, tan central a la ciencia ficción de los años sesenta, no ocurrió, pero lo temible es que los seres humanos nos estamos maquinizando, "algoritmizando" nuestras vidas. Algunos desarrollos de inteligencia artificial (donde está el big money de las grandes corporaciones tecnológicas) me resultan escalofriantes: tendremos chips implantados en nuestros cerebros que nos conectarán con redes neuronales globales. Las corporaciones ven eso como una gran ganancia, pero hay pocos debates sobre qué perderemos con eso. ¿Qué será aprender en ese nuevo contexto? ¿Cuál será la subjetividad humana que emerja de esta nueva configuración socio-técnica? ¿Podemos resistirnos a eso? Para mí esa es una conversación urgente, porque mientras nosotros estamos hablando de la OCDE, Google y Microsoft ya hicieron el chip y lo están vendiendo, y quizás incluso se lo venden a la OCDE con la promesa de que así les irá bien a todos los niños en las pruebas estandarizadas. Pero ¿para qué tomar pruebas si no será necesario aprender nada? Hay un cambio en ciernes en la condición humana y en la planetaria que me parece que hay que pensar, y hay alianzas políticas nuevas que hay que observar, aunque también diría que hay que activarse, hay que organizarse pronto, porque son cambios que ya están ocurriendo y en la que los "ciudadanos de a pie" e incluso los estados nacionales tenemos muy poca intervención.

P.: Fedicaria, el grupo editor de esta revista, es una plataforma de pensamiento crítico de profesores y profesoras que pugnan con los poderes al servicio de la mercantilización y homogeneización del conocimiento. En tu contexto profesional, ¿imaginas alguna práctica colectiva más allá del trabajo académico individual?

R.: Coincido con la importancia de los colectivos. Aunque las condiciones de trabajo académico son cada vez más individualizadoras, con las evaluaciones de impacto centradas en publicaciones en journals y otro tipo de indicadores similares, tenemos que imaginar, producir y defender formas de trabajo colectivas, sin las cuales la vida intelectual no tiene ningún futuro. En mi propia historia, sin incluir mi experiencia de activismo político, que también la tuve y fue muy importante en mi formación, diría que los grupos de investigación en FLACSO y en la Universidad de Buenos Aires fueron centrales para aprender con otros, y para crear programas de trabajo que 
Raimundo Cuesta y Marta Estellés, Consideraciones críticas sobre la mundialización...

tuvieron mucho impacto en la historiografía de la educación. Una de las experiencias más interesantes fue trabajar con cineastas y productores en la creación de videos educativos, porque son realmente creaciones colectivas que juntan saberes muy distintos; no es solamente la conversación entre pedagogos e historiadores, que al final de cuentas comparten unas cuantas referencias, sino también con el iluminador o con quien hace el montaje y la edición del material. Eso fue realmente desafiante como producción colectiva. Otros colectivos se armaron en torno a distintas propuestas de formación docente en las que participé o participo: crecimos mucho como grupos de trabajo, discutiendo desde el diseño hasta el día a día de cómo iban los cursos y qué producían en los docentes. Pero sobre todo creo que valoro el trabajo en los seminarios de formación, algo que aprendí estudiando con Tom Popkewitz. En Madison, las reuniones de los miércoles (el Wednesday Group) eran fundamentales para ir aprendiendo a leer y construir un lenguaje o una mirada común sobre la teoría y la investigación. Trato de hacer eso con mis doctorandos en el DIE en México, promoviendo seminarios donde leemos y discutimos textos, donde vale la palabra de todos, donde cada uno puede hablar desde su encuentro con el texto y aprender a escuchar las lecturas que hicieron los compañeros, donde se pueden presentar las ideas en borrador pero con la condición de que haya un trabajo de cada uno, un compromiso, para producir conocimiento entre todos. Son espacios de formación colectiva y de creación intelectual que se van enriqueciendo con una conversación sostenida, y que hay que defender de la "puntitis" y la mercantilización creciente de toda la actividad académica.

\section{CONTRIBUCIÓN AL DEBATE SOBRE LA MUNDIALIZACIÓN DE LOS SISTEMAS EDUCATIVOS DE...}

\section{THOMAS S. POPKEWITZ ${ }^{1}$}

El sentido del diálogo que esta mesa-debate abre es muy relevante, aunque puede contener su propia imposibilidad. La noción de "globalización" que da pie a la discusión dirige la atención hacia interconexiones más amplias que pueden pasar desapercibidas. Los significados de la globalización plantean tanto advertencias y peligros como posibilidades. Los peligros están en las imposiciones históricas que la palabra puede acarrear, organizando, clasificando y diferenciando la acción. Los lenguajes de la globalización portan consigo una razón comparativa. En un nivel, la globalización marca una época que yuxtapone el presente al pasado para presuponer

\footnotetext{
${ }^{1}$ La versión original en inglés puede consultarse en: http://links.uv.es/remK4TG
} 
unas diferencias que la desencadenaron. Al mismo tiempo, ciertamente los estándares caracterizan a la globalización en la actualidad. Los criterios que incorporan sus clasificaciones establecen diferencias de valor entre las naciones y los pueblos que se autodenominan, a modo de eslogan, Sociedades y Economías del Conocimiento de las que no lo son. Las divisiones soterradas en los discursos de la globalización se erigen como edificios estables y se expresan a menudo en las relaciones de poder que ejercen los flujos y movimientos del norte "globalizado" al toparse con el sur "no global". Las distinciones geográficas se convierten en categorías sobre los orígenes de los acontecimientos que causan, alivian y perturban las relaciones sociales y las experiencias personales. Los relatos sobre los orígenes evocan y eluden determinadas lógicas históricas de cambio que operan como conceptos transhistóricos del tipo de la difusión mundial del capitalismo y la institucionalización de las escuelas o los conceptos binarios de endógeno/exógeno, nacional/local.

El peligro de los neologismos de la globalización es que pueden superponer inadvertidamente las mismas representaciones, objetivaciones y la razón comparativa de los fenómenos como objeto de investigación y cambio en lugar de deshacerlos. El capitalismo es uno de esos ejemplos. A él se le atribuyen representaciones e identidades universalizadas particulares que diferencian estructuras y errores sociales. Sin embargo, esa universalización de las representaciones e identidades no explica las diferencias en las prácticas políticas y escolares del este de Asia, la antigua Unión Soviética; las diferencias entre los liberalismos de Europa oriental y occidental, que se formaron en Estados Unidos en el siglo XIX y continúan en la actualidad. EI capitalismo es una entidad inestable y su cosificación de las personas es fruto de poderes que se "mueven" en las intersecciones de varias líneas históricas en diferentes espacios y tiempos.

Esta discusión sobre la globalización y su problematización encadena con la segunda parte de esta mesa-debate sobre la investigación crítica y el cambio:

En España en las últimas décadas impera una neolengua de uso común tanto para gobiernos de izquierda como de derecha (competencias, niveles de rendimiento, estándares de aprendizaje...), que expresa el pacto no escrito sobre la educación y sus metas. ¿Constituye la impugnación de estos lenguajes una precondición del pensamiento crítico en educación? ¿Qué herramientas 
Raimundo Cuesta y Marta Estellés, Consideraciones críticas sobre la mundialización...

heurísticas se pueden utilizar para desenmascarar ese consenso universal sobre la escolarización?

Esta discusión plantea la cuestión sobre cómo entablar una conversación crítica sin caer en las lógicas o racionalidades que residen en las condiciones presentes. Como defiendo a continuación, una ciencia crítica de la educación atañe al cambio. Pero esta noción de cambio no se refiere a la planificación y gestión del futuro, pues la planificación para cambiar el presente, paradójicamente, produce estabilidad y exclusiones en su esfuerzo por enmendar los males sociales. El examen crítico que se propone es más bien una incisión del presente como método para desentrañar la propia estructuración del pensamiento y la acción que organiza el presente. Un compromiso crítico con el presente supone cuestionar las diferentes líneas históricas intersectoriales que dan sentido a lo que hace falta cambiar. Son las condiciones irreflexivas, poco o nada meditadas, las que hacen de la educación un objeto de intervención en la vida de las personas, para proporcionar escenarios históricos al consenso universal y para explorar la racionalidad de la política de la escolarización como ciencia crítica de la educación.

Usaré la expresión una ciencia crítica de la educación en un sentido que aúna dimensiones intelectuales, históricas y políticas. A menudo se piensa que la ciencia consiste en dar una atención disciplinar y sistemática al mundo. Esta concepción de la ciencia pasa por alto la colonización de esta palabra por los legados positivistas, empiristas y los procedentes o derivados de las lógicas cartesianas que rodean a la filosofía analítica en los estudios científicos. Este positivismo y empirismo reducen la ciencia al estudio de las representaciones y objetivaciones del mundo. Son las representaciones y objetivaciones del mundo y las personas lo que una ciencia crítica debe explorar en tanto que productos del poder y lo político. Esta ciencia crítica que busca "despensar" para poder pensar se centra en el estudio de los sistemas de razón o las reglas y normas que ordenan y clasifican lo que se aprende y se hace en la escuela. Sostengo que los criterios que establecen quiénes son y deberían ser los docentes y los niños es una cuestión de política educativa; esto significa que pensar que los niños aprenden competencias globales o alcanzan determinados niveles de rendimiento o estándares de aprendizaje es fruto de principios históricamente construidos en los que las ideas de "aprendizaje" dirigen la experiencia y el pensamiento. Estos principios de "fondo" son políticos en tanto que ordenan y clasifican la reflexión y la acción que crean los espacios de acción en las escuelas y 
Raimundo Cuesta y Marta Estellés, Consideraciones críticas sobre la mundialización...

en las actividades de los docentes. Lo político remite, entonces, a cómo la "razón" escolar constituye un instrumento para acotar lo que es (im)posible como reflexión y acción. Como argumentaré a continuación, los espacios de acción escolar y su investigación buscan la formación de unos tipos de personas que, paradójicamente, excluyen y abyectan aquellos a los que se pretende incluir.

La discusión se divide en tres partes. La primera parte se centra en la idea de los estudios críticos y la política de la escolarización. La segunda parte considera la razón de la escolarización como objeto de estudio y el problema de una ciencia crítica. La tercera parte examina cómo pensar para "despensar" puede convertirse en un objeto de un estudio crítico de la escolarización.

1. Una anécdota graciosa en mi camino a la investigación: cómo la investigación para la mejora de la educación "se convirtió" en estudios críticos de lo político.

2. Crítica y cambio como "pensar/despensar".

3. La razón de la escolarización como objeto de una ciencia crítica de la educación.

Mi enfoque se centra en la investigación educativa como actor social y cultural; actor en el sentido de que las distinciones y categorías de las ciencias de la pedagogía generan principios que dirigen la conducta. Esta actuación es política como lo son las líneas históricas en las que se desarrolla la investigación pedagógica en la disposición y clasificación de conductas. Este enfoque en la investigación escolar va a contracorriente. Se opone a la idea de que los profesores no utilizan la investigación en su enseñanza como una forma de pasar por alto la moneda de cambio de las ciencias de la educación en la escolarización. No se trata de si los profesores utilizan una investigación particular para planificar, sino de los principios que operan en lo que cuenta como práctica y experiencia en la escolarización.

UNA ANÉCDOTA GRACIOSA EN MI CAMINO A LA INVESTIGACIÓN: CÓMO LA INVESTIGACIÓN PARA LA MEJORA DE LA EDUCACIÓN "SE CONVIRTIÓ" EN ESTUDIOS CRÍTICOS DE LO POLITICO

Cuando comencé el programa de doctorado en la Universidad de Nueva York hace algunas décadas, la globalización significaba mirar a Ellis Island en la Bahía de Nueva York, donde mis padres entraron hace un siglo desde Europa. Mi investigación inicial de doctorado se centraba en The New Curriculum Reforms, un movimiento de 
reforma para repensar y experimentar con los modelos curriculares y la enseñanza relacionada con las ciencias, las matemáticas, la alfabetización y las ciencias sociales. El trabajo del psicólogo cognitivo Jerome Bruner The Process of Education (1960) fue una obra fundamental en estas reformas. La idea central era que el currículo debía enseñar los conocimientos más aplicables para comprender e interpretar el mundo y hacer que los niños reflexionaran sobre las estructuras disciplinarias básicas del conocimiento y los métodos. Inicialmente, yo iba a tomar la orientación psicológica de Brunner en mi propuesta de investigación de doctorado. Se trataba de desarrollar un currículum orientado a la investigación o al descubrimiento para niños y niñas de educación primaria. Con tono amable y gentil, Clemens, mi director, me dijo: "Por supuesto, lo que dices es interesante", pero añadió: "Eso es lo que todos hacen. ¿Por qué no tratar de pensar diferente sobre los problemas?". Mi traducción: “Oye, estúpido, no sólo lo que sugeriste es aburrido, sino que, además, has dado por natural e incuestionable lo que todo el mundo supone que es el cambio... ¿Concebido quizá de forma diferente? Si usted acepta las reglas existentes de razonamiento sobre la escolaridad y el cambio, justed se queda con esas reglas! Eso puede no ser muy productivo. De hecho, puede acabar contribuyendo a preservar las mismas cuestiones que pretenden cambiarse".

Comienzo con esta anécdota porque es más que un reflejo del "yo". Constituye una vía de entrada para explorar una ciencia crítica y la política del conocimiento escolar. Distingo lo político de su uso convencional que implica una noción de poder como "propiedad" de ciertos grupos para gobernar y diferenciarse de los "otros" que son los gobernados, lo que sucede a menudo con el capitalismo, que se universaliza y se convierte en una distinción binaria entre dominantes y dominados. La política, en esta noción de crítica, suele hacer referencia a los que toman las decisiones, los beneficiarios y los perjudicados en los acuerdos sociales e institucionales. El punto de partida $u$ origen del cambio son las posiciones sociales dadas a las representaciones dadas como las categorías que estructuran las desigualdades. La política de la reforma consiste en corregir las desigualdades, como la representación de los intereses de todas las partes interesadas, la escucha de la "voz" de los grupos marginados y desfavorecidos en la toma de decisiones educativas y la expresión de la cultura de las poblaciones anteriormente marginadas.

La sensibilidad a la hora de definir el poder se refleja en las referencias a la igualdad como las reformas que representan a todas las partes interesadas, a los stakeholders, y en las referencias a escuchar la "voz" de determinados grupos 
Raimundo Cuesta y Marta Estellés, Consideraciones críticas sobre la mundialización...

marginados y desfavorecidos en la toma de decisiones en materia educativa. En la década de 1960, esta política se reflejó en los esfuerzos de la Ciudad de Nueva York por responder al fracaso de las escuelas a la hora de educar a grupos pobres o de determinadas razas o etnias. La respuesta gubernamental y parte del movimiento de derechos civiles fue crear un sistema escolar más descentralizado en el que participaron grupos comunitarios locales. La cuestión de la participación en los distritos escolares descentralizados giraba en torno a cómo designar "grupos" para representar a "la comunidad"; quiénes eran formalmente constituidos como "grupos", para lo cual se requerían que las organizaciones pudieran demostrar su carácter "responsable"; y a quiénes excluir fuera de los límites de "lo razonable". La designación de grupos comunitarios y partes interesadas estaba vinculada a lo que era considerado aceptable a la hora de identificar y reconocer las relaciones de poder y los intereses sociales (Popkewitz, 1976).

La política de la representación y las nociones de voz y representación son importantes para los movimientos sociales, pero, si bien son necesarias, no son suficientes para explicar cómo opera el poder. Aquí me gustaría presentar una noción complementaria de poder, una que opera a través de la producción de principios que moldean y modifican lo que se dice y se hace. Jacques Rancière (2006b) llama a esta noción de lo político la partición de lo sensible y, yo añadiría, las sensibilidades (la relación de cognición y afecto generadas en la investigación). De manera similar, Foucault (1979) usa la palabra "gubernamentalidad" y Latour "gobernar a distancia". Todos ellos entienden que el poder no opera tanto a través de la fuerza bruta como del ordenamiento de la conducta. Esta noción de poder productivo se refiere a la forma en que las objetivaciones del mundo se convierten en modos de "ver", clasificar y actuar. Los primeros movimientos feministas enmarcados en esta noción de poder fueron capturados en la obra de Denise Riley Am I that Name? Feminism and the Category of 'Women' in History (1986). El libro examina históricamente las cambiantes construcciones históricas de la categoría "mujer", en tanto que un tipo particular de subjetividad efecto del poder que crea espacios de acción para "ver" la naturaleza del cuerpo. Desde esta misma perspectiva, lan Hacking sugirió que la distinción de Marx del "trabajador" con sus sensibilidades era una idea que se fue formando a través de los informes de inspectores de fábricas británicas durante la Revolución Industrial. Esta idea de cómo el conocimiento "actúa" para moldear y modelar lo que es (im)posible es importante para los estudios críticos. Dirige la atención a lo político. Lo político hace referencia a la producción de principios que moldean y modifican lo que 
se dice y se hace. Las cosas que suceden en el mundo (lo óntico) son en realidad descritas y esas descripciones incorporan principios que "actúan" sobre lo que se dice, se piensa y se hace para rectificar los errores sociales. Así, las representaciones, identidades y modelos de aprendizaje en las aulas son de hecho ejemplos de esta operación del poder productivo. Hablar sobre la infancia en términos de "aprendizaje" crea formas particulares de pensar sobre la "naturaleza humana" y las prácticas de intervención que hacen posible esa naturaleza deseada; la del buen adulto/ciudadano/padre/trabajador. Tras los conceptos de enseñanza y aprendizaje como motivación, autoestima, realización personal o empoderamiento, subyace la activación y actualización de la buena naturaleza. Para situar esto en la teoría social actual, la ontología y la epistemología deben considerarse parte del mismo fenómeno y no como algo separado.

Aquí es donde cobra sentido una ciencia crítica de la educación, pues desafía las particiones de lo sensible. Si vuelvo al caso de mis estudios de doctorado (como un acto de producción de memoria que se introduce en el presente como pasado), en aquel momento comencé a leer sobre un campo del que no sabía nada, la llamada "sociología del conocimiento". La sociología del conocimiento examina cómo el conocimiento que tenemos de la ciencia y la vida cotidiana no se trata simplemente de "nuestras" experiencias, sino de las condiciones históricas que hacen que la experiencia sea posible de reconocer. Joan Scott (1991), una historiadora feminista, dejó bien clara esta cuestión cuando examinó las reflexiones de una escritora gay que entró en unos baños públicos de San Francisco en los años sesenta. Tal y como argumentó, la expresión personal de pertenencia y la sensación que entrañaba entrar en unos baños públicos era histórica y política, así como personal en tanto que la experiencia en sí misma está relacionada con la memoria colectiva disponible para hacerla "compartida". En el ejemplo de Scott de la experiencia gay en los baños públicos de San Francisco, es posible pensar más en lo político, pues lo que le da inteligibilidad al yo y a la sociedad incorpora dos características adicionales que se forman como objetos de un estudio crítico. Una es cómo los deseos se construyen e integran en la lógica y razón de la escolarización. Si me centro en la evaluación del Programa para la Evaluación Internacional de Estudiantes (PISA) llevado a cabo por la Organización para la Cooperación y el Desarrollo Económicos (OCDE), que a partir de 2000 se viene aplicando a miles de escolares de 15 años, en cada vez más países, sean o no de la OCDE, las estadísticas, clasificaciones y comparaciones actúan como deseos. Como he escrito recientemente, PISA es ciertamente como un espacio teórico 
Raimundo Cuesta y Marta Estellés, Consideraciones críticas sobre la mundialización...

desprovisto esencialmente de teoría que examina cómo los muchísimos números que genera y sus evaluaciones y sus clasificaciones nacionales se refieren a las potencialidades de las sociedades de hoy que las investigaciones autorizan a funcionar como tecnologías para decir la verdad sobre las naciones y las personas. De hecho, lo que genera la aplicación de este programa son principalmente deseos particulares sobre la organización de la sociedad y los tipos de personas, que terminan definiéndose por sus reglas y los estándares de razón que sostienen. Como tal, las evaluaciones internacionales conectan de hecho la política nacional, la investigación y la organización de la vida social para crear nuevos espacios sociales de acción a través de sus codificaciones y estandarizaciones (Popkewitz, en prensa).

En este orden de cosas, para decirlo más concretamente, el ranking de los países funciona como una especie de GPS. Donde quiera que uno esté en el mundo, puede ubicarse colectivamente como nación e individualmente en relación con otros, en algunos casos en la parte superior, otros en el medio y otros en la parte inferior. Pero los gráficos y cuadros que encarnan tales deseos requieren a su vez acciones preventivas contra los peligros imaginados. Estos peligros incorporan dimensiones afectivas generadas a través de las medidas promovidas por el temor a perder posiciones superiores o no llegar a la cima.

Sin embargo, los deseos encarnados en la razón de la escolarización también conllevan una diferenciación entre cuáles son las potencialidades que se esperan de las personas para ser una Sociedad del Conocimiento y la población peligrosa para hacer efectiva esa promesa. Las escalas y jerarquías de los países "exitosos" y menos exitosos aparecen en PISA, por ejemplo, como meras abstracciones que funcionan como coordenadas sobre el nivel de modernización y progreso. Estas clasificaciones de los países en función de su rendimiento escolar imponen a las personas una serie de valores que marcan la diferencia entre la normalidad y la patología (Popkewitz, 2018). Los números y cualidades comparativas sobre los países portan consigo complejas estructuras formadas a partir de microcategorías sobre las disposiciones de las personas (la motivación de los niños, las interacciones de los padres, las "mentalidades de los maestros") que son, en última instancia, ideales filosóficos.

Estos ideales se forman a través de las cualidades epistémicas que clasifican y determinan quién es y cómo debe ser el niño. Los estándares de alto rendimiento operan como ideales filosóficos sobre lo que una sociedad y una persona deberían ser a través del GPS que compara las características y capacidades de las personas con lo que se desea (el niño motivado y con "agallas") y lo que interfiere y dificulta el 
Raimundo Cuesta y Marta Estellés, Consideraciones críticas sobre la mundialización...

desarrollo potencial del niño. Este conocimiento sobre el niño se centra en las cualidades y características del niño, la familia y la comunidad en tanto que disfunciones o patologías para lograr ese ideal; es decir, en las cualidades del niño que se queda atrás, que está en desventaja o riesgo de no estar en el promedio y, por tanto, de que no llegue a ser el niño deseado.

Una ciencia crítica sobre la política de escolarización hace visible cómo se forman los problemas, los métodos y las soluciones en la rectificación de los problemas sociales y personales para diferenciar, dividir y excluir en sus esfuerzos en pos de la inclusión; es decir, cómo las reglas y los estándares de la razón de la escolarización dirigen y clasifican la experiencia diferenciando a las personas. Hoy en día, este interés aparece reflejado en lo que se ha denominado como "posmodernismo", poshumanismo, poscolonialismo y estilos post-fundacionales de razonamiento sobre la investigación y la vida social. Los "posts" suelen significar una postura crítica para evitar la idealización, pero, además, siempre guardan alguna relación con lo que no es "post".

\section{CRÍTICA Y CAMBIO COMO "PENSAR/DESPENSAR"}

Esta preocupación por la "razón" como objeto de estudio material e histórico se relaciona con la "sociología del conocimiento", así como con la pregunta que se plantea en esta mesa-debate sobre la necesidad de utilizar herramientas intelectuales que desafíen el acuerdo tácito sobre los lenguajes como condición del pensamiento crítico en educación.

La noción de ciencia crítica puede relacionarse con el giro de Bruno Latour (2004) de examinar lo que en investigación se da por sentado que deben ser asuntos de interés para investigar en tanto que preocupaciones sobre lo que importa. Esta noción dirige la atención hacia "lo que es aceptado como autoridad a través de una crítica de las condiciones sobre lo que se sabe, lo que se debe hacer, lo que se puede esperar" (Foucault, 1984, p. 38; cursivas del autor). Parafraseando la célebre XI tesis de Karl Marx (1976) sobre Feuerbach (1845), este trabajo se dedica a las ciencias humanas no solo para interpretar el mundo, sino también para encontrar conocimiento que tenga la posibilidad de cambiarlo (véase, por ejemplo, Llewelyn, 2004).

Ciertamente, este no es el uso común de la palabra "crítica". En el entorno estadounidense, a menudo se equipara lo "crítico" con algo negativo, cuando el verdadero desafío de la investigación es producir mejoras sociales y vías para el progreso. El enfoque optimista tiene prioridad a la hora de discutir sobre la búsqueda 
de conocimiento práctico y lo que la ciencia debería hacer. $\mathrm{Y}$ sin mencionar explícitamente quién es el agente, la ciencia y el mundo carecen de su humanismo y determinismo.

He defendido en otro lugar que las nociones de humanismo y determinismo son efectos del poder que conservan el orden de las cosas y trabajan contra los compromisos sociales como objeto de cambio (Popkewitz, en prensa). La ciencia crítica implica una noción de agencia (o acción humana) y cambio que viaja en un registro diferente del que se hallan las ideas convencionales de política. Estas ideas convencionales tienen una concepción humanista de la agencia que considera la intencionalidad humana como el único agente causal.

El reto de la agencia, en contraste con el humanismo, es hacer visibles las formas habituales de pensar sobre la sociedad y las personas como políticas. La agencia, entonces, es la "puesta a prueba de los límites del presente, liberándonos del dogma particular del presente a través de una resistencia a lo que parece inevitable y necesario modificando las reglas del juego, hasta cierto punto" (Foucault, 1984, p. 48). Esa vacilación implícita en el "hasta cierto punto" está relacionada con la condicionalidad del presente que hace imposible encontrar un conocimiento completo y definitivo sobre lo que constituye el pasado y el presente.

La crítica fue un elemento importante en las tradiciones ilustradas preocupadas por la libertad, pero de alguna manera se ha ido quedando apartada en el camino hacia el presente. Lo que se entiende como libertad es la búsqueda de conocimiento técnico que pueda aplicarse directamente para cambiar condiciones y personas. El filósofo e historiador social alemán Hans Blumenberg (1966/1983) sostiene que la Ilustración cosmopolita preocupada por la razón, la racionalidad y el progreso tiene dos lados complementarios ${ }^{2}$. Uno que evolucionó hacia la planificación social y las intervenciones, que crean una jerarquía entre los que saben y los que deben saber. Los usos curriculares de modelado infantil en la educación matemática reflejan perfectamente esta noción de conocimiento y agencia: los niños aplican distintos modelos científicos para explicar el mundo e interpretar sus propias experiencias. El otro lado de la "razón" esencial en las ideas de progreso de la llustración implica una noción diferente de la ciencia, aquella que Blumenberg denominó "renuncia" y Lynn Fendler describió como "dar la voz de alarma" (en inglés, whistle blowing).

\footnotetext{
2 En el libro editado que hice con Lynn Fendler (Popkewitz y Fendler, 1999), exploramos las diferentes epistemes con las que se evoca la palabra "crítico" en educación.
} 
La noción de renuncia y de dar la voz de alarma considera el cambio como la posibilidad de rechazar lo que las personas son y deberían ser. El cambio no radica en el gobierno de "instituciones determinadas por la ideología y guiadas por circunstancias pragmáticas", sino en hacer visible la objetivación de la vida social como históricamente construida con "sus propias regularidades, lógica, estrategias, justificación y 'razón'” (Foucault, 1991, p. 5). Esta historización supone cuestionarse permanentemente cómo llegamos al presente -con sus correspondientes límites- y se trata de un método para pensar quiénes somos y qué debemos hacer para cambiar. Volviendo de nuevo a Foucault:

La crítica consiste en eliminar ese pensamiento y tratar de cambiarlo: para mostrar que las cosas no son tan evidentes como se piensa y para ver que lo que se acepta como evidente ya no será aceptado como tal. Practicar la crítica consiste en hacer difíciles los actos sencillos (Foucault, 1988, pp. 155-156).

Así, la crítica es optimismo sobre las posibilidades de cambio. Ese optimismo en el cambio consiste en hacer inestable lo que se da por sentado y natural "vinculándolo más a las circunstancias que a las necesidades, que son más arbitrarias que evidentes; se trata más de una cuestión de circunstancias históricas complejas, pero temporales, que de constantes antropológicas inevitables" (Foucault, 1988, p. 156). La investigación crítica consiste en "despensar" para pensar y actuar con grados de libertad que requieren, en mi opinión, un método histórico particular de estudio del presente.

\section{LA RAZÓN DE LA ESCUELA COMO OBJETO DE UNA CIENCIA CRÍTICA DE LA EDUCACIÓN}

A comienzos del siglo XX, el importante filósofo intelectual John Dewey escribió su libro How We Think que ha viajado a través de los océanos. Este icono de la psicología antropológica de la educación progresiva estadounidense cuestiona en esta obra cómo "nosotros" pensamos y experimentamos en tanto que constituidos histórica, social y culturalmente. Desde Dewey, nos preguntamos cómo se le da inteligibilidad a sus escritos en diferentes momentos y lugares; para que las personas "razonen" -piensen y actúen- de manera que la psicología pragmática "tenga sentido" sobre lo que "nosotros" hacemos en nuestra vida social, compromisos políticos y, aún más cerca, en las escuelas, con los que consideramos niños, y con nuestros deseos de cambio. 
Raimundo Cuesta y Marta Estellés, Consideraciones críticas sobre la mundialización...

Permítanme continuar con este pensamiento sobre la razón de la escolarización y lo político haciendo que la idea de mejora de la enseñanza -lugar común en la reforma escolar- sea un objeto empírico para un estudio crítico. La idea de que la investigación mejora la enseñanza camina de la mano con la idea de que el cambio tiene que ver con la mejora social. La literatura contemporánea sobre la profesionalidad docente afirma que el objeto de las profesiones es la mejora social; y si los investigadores arreglan lo que hacen los maestros, guían a las familias en la crianza de sus hijos y apoyan una vida comunitaria saludable, entonces contribuyen a la creación de una sociedad mejor con más felicidad personal y menos males sociales.

Pero, ¿qué sucede si tratamos las ideas de "mejora" como un evento empírico y no asumimos nuestro trabajo como el objeto de la escolarización? Esta idea se puede tratar como un medio para entender lo político en la escuela pues la "mejora" presupone un deseo humano natural y restringe la posibilidad de actuar. La mejora tiene una trayectoria histórica particular que organiza y cambia la vida de las personas para que puedan hacer y aprender mejor $y$, por tanto, ser alguien diferente al que seríamos si no participamos en esa "mejora". Este tipo de pensamiento crítico no utiliza las categorías escolares existentes, sino que se cuestiona cómo esas categorías sobre la psicología y la sociología del niño, por ejemplo, se conectan con las ideas de "mejora". Estas conexiones y ensamblajes generan principios sobre quiénes somos, debemos ser y quiénes no "encajan" adecuadamente en los ideales de niño que se desean.

"Mejorar" el estudio empírico significa, entonces, "ver" la mejora como un evento histórico. La mejora social es una invención del siglo XIX que se gesta cuando los cambios culturales permitieron a las personas pensar su vida como una trayectoria planificada y articulada en torno al desarrollo de su carrera profesional. La idea de una carrera apareció concomitantemente con el surgimiento de teorías sociales que buscaban estandarizar a las personas. La invención de la "mejora social" dispuso los asuntos sociales en un momento que podían modelarse para lograr un cambio (Popkewitz, en prensa). Se empezó a asumir que lo natural era colocar a las personas en "una flecha de tiempo", un ordenamiento de la vida de las personas y de las instituciones que podía regularse a través de ideas lineales de desarrollo y crecimiento. El aula graduada por edades de finales del siglo XIX capturó a la perfección esa noción de la flecha del tiempo.

Esta presunción de un tiempo regular conectó con la idea de que las personas pueden ser manejadas a través del control del tiempo social, vinculada a las teorías 
liberales sobre cómo se rige la individualidad y la sociedad. Hoy en día, esta idea de "mejora" parece existir en la investigación y la política en el estudio de procesos y patrones de comunicación. El sobreentendido tácito es que todo lo que se necesita es una adecuada combinación de políticas e investigación para que ese cambio tenga lugar.

La mejora implica, por tanto, reglas y estándares particulares de "razonamiento" sobre cómo gestionar y cambiar a las personas. Esta gestión, gobierno y cambio es la política de la escolarización. Si uno acepta esta idea de mejora en su afán por explorar cómo una ciencia crítica abarca lo político, tres principios se conectan históricamente con esta noción del tiempo para formar la política de la escolarización y para definir lo que es posible.

En primer lugar, la educación y su investigación para mejorar lo que hacen los maestros y los niños tienen que ver históricamente con la formación de tipos de personas. El lenguaje de hoy en día habla de ayudar al aprendizaje de los niños -con el maestro como facilitador, afectuoso, etc.-, pero históricamente elude más de lo que ilumina. Cuando se examinan las nociones de crecimiento y desarrollo, incluso de aprendizaje, estas tienen que ver con cambiar a las personas a través de la escolarización. Los niños son enviados a las escuelas para que se conviertan en algo que no serían si no fueran "educados".

El deseo de educar e investigar para cambiar a las personas no es tan desconcertante históricamente. La formación de las repúblicas en Europa y América del Norte reconoció la educación como un elemento importante para el gobierno. La persona deseada se llamó ciudadano. El ciudadano era un modo particular de vida que implicaba la participación necesaria para que la nueva forma de gobierno republicano funcionara (Cruikshank, 1999; Wood, 1991). En la escuela moderna, la intervención y planificación tenían lugar en el interior del niño (véase, por ejemplo, Ó, 2003; Horlacher, 2015). Las pedagogías francesas y portuguesas a principios del siglo XX, por ejemplo, observaron y "registraron" la vida física y moral interna para mapear la espiritualidad del sujeto educado ("el alma humana") que contribuyó a la vida social (Ó, Martins y Paz, 2013).

En la psicología residía el conocimiento sagrado para cambiar a las personas. $A$ comienzos del siglo XX, los American Child Studies de G. Stanley Hall hablaban de la ciencia como si se tratara de una fuente generadora de los principios culturales necesarios para cambiar a las nuevas poblaciones de inmigrantes y grupos étnicos que asistían a la escuela y crear una sensación de pertenencia colectiva. Hall 
argumentó que la psicología de la adolescencia se centró en el "alma" del niño. La psicología se preocupaba por las cualidades morales internas y las características de las personas que hoy se denominan "disposiciones" y "creencias" de las personas. La ciencia proporcionó estos principios culturales a través del "método más complejo de observación, descripción e inducción" que permitiría "conquistar la naturaleza" y desarrollar "la razón, la verdadera moral, religión, simpatía, amor y disfrute estético" del niño (Hall, 1904/1928, p. vii).

La idea de mejora social da cuerpo a una serie de líneas históricas generadoras de principios sobre cómo hacer determinados tipos de personas. Esa formación no consiste simplemente en modelar el comportamiento. Se trata también de conquistar el interior del niño o su "alma".

En segundo lugar, las ciencias de la infancia y la pedagogía eran preventivas. Preventivas, en el sentido de que hablar sobre el desarrollo y el crecimiento del niño implica una proyección de las potencialidades de la sociedad que el niño encarna a través de la pedagogía. Este deseo se forma a través de los sistemas de razón que organizan lo que se dice, piensa y actúa. Las distinciones, categorías y diferenciaciones que dirigen la escolarización se convierten en la definición funcional del cambio en la escolarización y sus ciencias. Las palabras que hablan sobre el aprendizaje y el desarrollo de los niños no son simplemente un bien universal que la investigación promueve. Las categorías y distinciones del aprendizaje hablan sobre el futuro en tanto que generan visiones utópicas sobre las potencialidades de las personas, siempre y cuando la investigación y la enseñanza hagan su trabajo correctamente. Hablar de aprendizaje es hablar de deseos dirigidos a lo que se debe ser y lo que los maestros y los niños conciben como satisfacción, autoestima, motivación... Es decir, todas palabras que encarnan el afecto. El ideal contemporáneo de alumno para toda la vida que produce la escuela es un deseo sobre las potencialidades de las personas y los tipos de sociedades que la investigación y los programas se ocupan de actualizar.

Tercero, los deseos de mejoras sociales poseen dos gestos: esperanzas de que el niño se convierta en lo deseado que simultáneamente generan temores de convertirse en persona peligrosa que amenaza lo que se esperaba epistémicamente. Cuando los objetos de planificación e investigación en el aula son despojados de sus dimensiones morales, la idea de cambio encarna las potencialidades del niño y el maestro. La noción de niño creativo, por ejemplo, es una forma particular de pensar, diferenciar y ordenar lo que debe ser el niño que simultáneamente compara y excluye 
al niño que no es "creativo". El trabajo de Catarina Martins (2017, 2018), por ejemplo, explora cómo la idea de creatividad y de artistas aparece en el siglo XIX como un concepto vinculado al de ciencia. Los conceptos incorporan distinciones y diferencias; en este caso, la idea de creatividad porta implícitamente la imagen de quién no es ese tipo de niño.

Esta formación de tipos de personas y diferencias con su doble gesto, que es también una suerte de doble cara, es históricamente evidente en la creación de asignaturas escolares como arte, matemáticas, música o ciencias. El curriculum escolar es como una alquimia, esto es, el movimiento de espacios disciplinarios de producción de conocimiento (por ejemplo, física, arte, historia) en los espacios escolares. Irónicamente, la alquimia en la escuela no tiene nada que ver con el aprendizaje de las materias escolares. Por supuesto, los símbolos y artefactos de las disciplinas, como los microscopios en ciencias o los instrumentos en música, se introducen en la escuela, pero los conceptos y clasificaciones de las disciplinas operan como prácticas que normalizan y patologizan las características y capacidades de las personas. La ciencia, por ejemplo, enseña a los niños a vivir, de ahí que los indicadores de competencia científica se relacionen más con distinciones sociales y culturales que con prácticas científicas en sí mismas.

Mi perspectiva sobre los dobles gestos de la razón de la escolarización pone de relieve cómo la pertenencia, la exclusión y la abyección son la expresión de dos sentimientos y pensamientos aparentemente opuestos o dobles gestos de la misma expresión. El curriculum escolar y la investigación incorporan creencias sobre la esperanza de hacer que los niños participen en la sociedad que simultáneamente crean miedos. La resolución de problemas, la motivación, el aprendizaje, la autorrealización y el desarrollo son distinciones sobre las cualidades de las personas: las distinciones generan determinadas disposiciones hacia las personas que no tienen estas cualidades (el niño que no se realiza, desarrolla y aprende). Los temores son hacia las personas peligrosas expulsadas de los espacios de pertenencia: el niño "atrasado" de principios del siglo XX que luego se convierte en el niño desmotivado y perezoso que carece de autoestima y coraje o, como se dice en Estados Unidos, sin "agallas". La producción de lógicas comparativas y dobles gestos para generar diferencias históricamente se mezcla con cuestiones de racismo, eugenesia y con lo que Jill Casid (2015) denomina "la maquinaria colonial de dominación" (p. 122).

Llegados a este punto, cabe preguntarse si no es eso lo que deberían hacer las escuelas o si acaso las escuelas modernas no deberían cambiar a los niños para que 
Raimundo Cuesta y Marta Estellés, Consideraciones críticas sobre la mundialización...

se conviertan en ciudadanos productivos y reflexivos de la sociedad. Y la respuesta es: "Sí, por supuesto". Pero, si bien esto no es algo intrínsecamente malo, siempre existe el peligro de que los principios particulares ordenen y clasifiquen a las personas, de ahí que necesiten ser continuamente examinados.

\section{UNA CIENCIA CRÍTICA Y LA PARADOJA DE LA RAZÓN COMPARATIVA DEL CAMBIO}

El cosmopolitismo de la llustración europea y americana que defendía el uso de la razón humana y la ciencia para lograr la perfección humana encarnaba un modo particular de vida asociado al cultivo moral y una diferenciación entre las civilizaciones avanzadas y las menos avanzadas. Los civilizados y las civilizaciones de la llustración inglesa, francesa y estadounidense ubicaron y diferenciaron a las personas en tanto que la confianza en el progreso caminaba pareja al miedo a la degeneración y la decadencia. "Civilizar" para dotar a todos los seres humanos de un común suponía, en realidad, colocar a la humanidad en un continuo de valor y jerarquía que ordenaba y dividía a personas, razas y civilizaciones.

Hoy en día apenas se habla sobre civilizados y no civilizados en educación; "Nosotros" somos más civilizados que eso. Las distinciones entre lo civilizado y lo no civilizado están inscritas en las normas de desarrollo y las nociones de aprendizaje y error. Así, se distingue entre aquellos que tienen éxito porque están motivados de aquellos que "fallan" debido a su falta de "motivación", autoestima, eficacia o debido a su "fragilidad familiar".

La política de la escolarización está incrustada en la razón que dictamina lo que se dice y se hace. La ciencia crítica acepta el cosmopolitismo de la llustración como una actitud sobre la razón y la ciencia que permite un espacio de libertad para hacer cosas que antes no se concebían como posibles. La investigación hace frágil lo que parece natural e inevitable en nuestra forma de pensar sobre la libertad y, por lo tanto, abre alternativas fuera de las incluidas en los marcos contemporáneos. El cambio no es pronosticar el futuro, sino desnaturalizar lo que se toma como natural y, por lo tanto, abrir espacios para hacer posibles alternativas que están fuera de lo que se da como el orden de las cosas.

\section{REFERENCIAS}

Blumenberg, H. (1966/1983). The legitimacy of the modern age (R. Wallace, Trans.). Cambridge: MIT. 
Raimundo Cuesta y Marta Estellés, Consideraciones críticas sobre la mundialización...

Bruner, J. (1960). The process of education. Cambridge, MA: Harvard University Press (El proceso de la educación. México: Unión Tipográfica Editorial Hispano Americana, 1963).

Carney, S., Rappleye, J. y Silova, I. (2013). Entre la fe y la ciencia: la teoría de la cultura mundial y la educación comparada. Profesorado, 17(1), 243-267.

Casid, J. (2015). Scenes of projection. Recasting the enlightenment subject. Minneapolis: University of Minnesota Press.

Chang, H. J. (2012). 23 cosas que no te cuentan sobre el capitalismo. Barcelona: Debate.

Cruikshank, B. (1999). The will to empower: Democratic citizens and the other subjects. Ithaca, NY: Cornell University.

Cuesta, R. (2020). Creaciones prodigiosas: disciplinas escolares e historia del curriculum. Monográfico sobre la historia del curriculum en Historia de la Educación, 38, (en prensa).

Deleuze, G., \& Parnet, C. (1977/1987). Dialogues (H. Tomlinson \& B. Habberjam, Trans.). New York: Columbia University Press.

Dussel, I. (2003). Uniformes escolares y la disciplina de las apariencias. Hacia una historia de la regulación de los cuerpos en el sistema educativo moderno. En Popkewitz, T. S., Franklin, B. M. y Pereyra, M. A. (comps.), Historia cultural y educación. Ensayos críticos sobre conocimiento y escolarización (pp. 208-246). Barcelona: Pomares

Dussel, I. y Caruso, M. (2000). La invención pedagógica del aula. Una genealogía de las formas de enseñar. Buenos Aires: Santillana.

Eatwell, R., \& Goodwin, M. (2019). Nacionalpopulismo: por qué está triunfando y de qué forma es un reto para la democracia. Barcelona: Ediciones Península.

Foucault, M. (1991). Governmentality. In G. Burchell, C. Gordon, \& P. Miller (Eds.), The Foucault Effect: Studies in governmentality: With two lectures by and an interview with Michel Foucault (pp. 87-104). Chicago: University of Chicago Press. ("La gubernamentalidad". En M. Foucault, Espacios de poder, pp. 9-26. Madrid: La Piqueta, 1981).

Foucault, M. (1991). A question of method. In G. Burchell, C. Gordon, \& P. Miller (Eds.). The Foucault effect: Studies in governmentality (pp. 73-86). Chicago: University of Chicago Press.

Foucault, M. (1988). The care of the self: The history of sexuality (Vol. 3). New York: Vintage House. 
Raimundo Cuesta y Marta Estellés, Consideraciones críticas sobre la mundialización...

Foucault, M. (1984). What is an author? In P. Rabinow (Ed.), The Foucault Reader (pp. 101-120). New York: Pantheon Books (“¿Qué es un Autor?”. Editado por ElSeminario.com.ar, 2000-2005).

Foucault, M. (1984). What is the enlightenment? Was ist Auflärlung? In P. Rabinow (Ed.), The Foucault Reader (pp. 32-51). New York: Pantheon Books.

Foucault, M. (1979). Governmentality. Ideology and Consciousness, 6, 5-22. ("La gubernamentalidad”. En M. Foucault, Espacios de poder, pp. 9-26. Madrid, La Piqueta, 1981).

Hajisoteriou, C., \& Angelides, P. (2013). The politics of intercultural education in Cyprus: Policy-making and challenges. Education Inquiry, 4(1), 103-123.

Hall, G. S. (1904/1928). Adolescence: Its psychology and its relation to physiology, anthropology, sociology, sex, crime, religion, and education (Vol. 1). New York: Appleton and Co.

Latour, B. (2004). Politics of nature. How to bring the sciences into democracy (C. Porter, Trans.). Cambridge: Harvard University Press.

Llewelyn, J. (2004). Seeing through God: A geophenomenology. Bloomington: Indiana University Press.

Luis, A. y Romero, J. (2006). Pensando sobre la obra de... Miguel Ángel Pereyra. ConCiencia Social, 10, 83-118.

Luis, A. y Romero, J. (2007). Escuela para todos: conocimiento académico y geografía escolar en España (1830-1953). Santander: Universidad de Cantabria.

Luzón, A. y Torres, M. (2012). The Scholardship Thomas Popkewitz, 1970-2013. En Pereyra, M. A. y Franklin, B. M. (Ed.), Systems of Reason and The Politics of Schooling. School Reform in the Tradition of the Thomas S. Popkewitz (pp. 2564). New York \& London: Routledge.

Martins, C. S. (2013). Genius as a historical event: Its making as a statistical object and instrument for governing schooling. In T. S. Popkewitz (Ed.), The "reason" of schooling: Historicizing curriculum studies, pedagogy, and teacher education (pp. 99-114). New York: Routledge.

Martins, C. S. (2015). Disrupting the consensus: Creativity In European educational discourses as a technology of government. In T. S. Popkewitz (Ed.), The "reason" of schooling: Historicizing curriculum studies, pedagogy, and teacher education (pp. 99-114). New York: Routledge.

Martins, C. S. (2017). From scribbles to details: The invention of stages of development in drawing and the government of the child. In T. S. Popkewitz, J. Diaz, \& C. 
Raimundo Cuesta y Marta Estellés, Consideraciones críticas sobre la mundialización...

Kirchgasler (Eds.), A political sociology of educational knowledge: Studies of exclusions and difference (pp. 105-118). New York: Routledge.

Martins, C. S. (2018). The alchemies of the arts in education: Problematizing some of the ingredients of the recipe. In B. Jörissen, L. Unterberg, L. Klepacki, J. Engel, V. Flasche \& T. Klepacki (Eds.), Spectra of transformation (pp. 51-67). Munster and New York: Waxmann.

Marx, K. (1976). Theses on Feuerbach (written in the spring of 1845). In F. Engels (Ed.), Ludwig Feuerbach and the end of classical German philosophy (pp. 6165). Peking: Foreign Languages Press.

Morin, E. (2006). El Método 5: La humanidad de la humanidad. La identidad humana. Madrid: Ediciones Cátedra.

Ó, J. R. d. (2003). The disciplinary terrains of soul and self-government in the first map of the educational sciences. In P. Smeyers \& M. Depaepe (Eds.), Beyond empiricism: On criteria for educational research (Studia Paedagogica 34) (pp. 105-116). Belgium: Leuven University Press.

Ó, J. R. d., Martins, C. S., \& Paz, A. L. (2013). Genealogy of history: From pupil to artist as the dynamics of genius, status, and inventiveness in art education in Portugal. In T. S. Popkewitz (Ed.), Rethinking the history of education: Transnational perspectives on its questions, methods, and knowledge (pp. 157178). New York: Palgrave.

Osterhammel, J. (2015). La transformación del mundo: una historia global del siglo $X I X$. Barcelona: Editorial Crítica.

Popkewitz, T. S. (2003b). La producción de razón y poder: historia del curriculum y tradiciones intelectuales. En Popkewitz, T. S., Franklin, B. M. y Pereyra, M. A. (comps.), Historia cultural y educación. Ensayos críticos sobre conocimiento y escolarización (pp.146-184). Barcelona: Pomares.

Popkewitz, T. S. (2017). Historia transnacional comparada. Pensando en el yo y en el otro. Historia de la Educación, 36, 189-205.

Popkewitz, T.S. (2018). Anticipating the future society: The cultural inscription of numbers and international large-scale assessment. In S. Lindblad, D. Pettersson, \& T. Popkewitz (Eds.), Education by the numbers and the making of society: The expertise of international assessments (pp. 222-228). New York: Routledge.

Popkewitz, T.S. (en prensa). The impracticality of practical research: A history of sciences of change that conserve. Ann Arbor Ml: University of Michigan Press (en proceso de traducción al español por Octaedro de Barcelona). 
Raimundo Cuesta y Marta Estellés, Consideraciones críticas sobre la mundialización...

Popkewitz, T. S., \& Fendler, L. (Eds.). (1999). Critical theories in education: Changing terrains of knowledge and politics. New York: Routledge.

Popkewitz, T. S., Franklin, B. M. y Pereyra, M. A. (comps.) (2003). Historia cultural y educación. Ensayos críticos sobre conocimiento y escolarización. Barcelona: Pomares.

Rancière, J. (2006). The politics of aesthetics (G. Rockhill, Trans.). New York: Bloomsbury Academic.

Romero, J. (2001). La clase artificial. Recursos informáticos y educación histórica. Madrid: Akal.

Romero, J. y Estellés, M. (2020). La historia del currículum en España: la ruralidad dual de un subcampo todavía en construcción. Monográfico sobre la historia del curriculum en Historia de la Educación, 38, (en prensa).

Scott, J. (1991). The evidence of experience. Critical Inquiry, 17, 773-797.

Tedesco, J. C. (2005). Opiniones sobre política educativa. Buenos Aires: Granica.

Wood, G. S. (1991). The radicalism of the American Revolution. New York: Vintage Books. 